\title{
LA AFINIDAD. UNA INVESTIGACIÓN HISTÓRICA, JURÍDICA Y RELIGIOSA
}

\author{
POR \\ María Rosa Corazón CoRAzón \\ Doctora en Derecho, Abogada del Tribunal de la Rota \\ de España y de Tribunales Eclesiásticos
}

\section{RESUMEN}

La afinidad y su efecto en posterior matrimonio con familiar del cónyuge anterior, ha supuesto una investigación histórica, jurídica y religiosa desde 1753 a.e.c. hasta el siglo XXI, con fiel reflejo en la historia religiosa de España y del mundo hispánico, no realizada hasta ahora, y permite afirmar que el impedimento matrimonial de afinidad tiene sus orígenes en la más remota antigüedad y es el que mayor variación ha experimentado en la historia.

PALABRAS ClAVES: Afinidad. Parentesco. Conflictos. Historia de su regulación desde el siglo XVI a.e.c. al vigente siglo XXI. Matrimonio posterior con pariente afín, ¿prohibido, permitido? ¿Es nulo? ¿Hay incesto?

\section{AFFINITY. AN INVESTIGATION HISTORICAL, LEGAL AND RELIGIOUS}

\begin{abstract}
Affinity and its effect on another subsequent marriage with a relative of the first partner, has required an historical, legal and religious research, from 1753 b.C. until the XXI century with a accurate reflexion in both the religious history of Spain and into the Hispanic world, unknown until now, thus allowing to state that the affinity marriage impediment has its origins in the most ancient times and has had the biggest variation in history.
\end{abstract}

KEY WORDS: Affinity. Kinship. Conflicts. History of its regulation from the 16th century B. C. until the twenty-first century. Subsequent marriage with affines, prohibited, permitted? Is it void? Is there incest?

Recibido/Received 2010-06-11

Aceptado/Accepted 2010-09-10 
La afinidad es la relación que media entre un cónyuge y los familiares de su consorte. De ella se pueden destacar dos aspectos, el primero que es un parentesco, realidad social con reconocida trascendencia jurídica para múltiples aspectos de la vida y el segundo, su efecto en posterior matrimonio, prohibiéndolo en determinados supuestos.

El parentesco de afinidad proviene de considerar que los familiares de un cónyuge son, en alguna medida, también familiares del consorte.

La prohibición para contraer matrimonio por razón de afinidad se encuentra desde la más remota antigüedad y subsiste hasta hoy. Esta prohibición ha experimentado múltiples variaciones a lo largo de su vigencia, tanto en la sociedad civil como en la eclesiástica.

La denominación de impedimento matrimonial es noción del Derecho Canónico, mientras que en el Derecho Civil se contempla como prohibición para el matrimonio. No obstante, el impedimento matrimonial también prohíbe el matrimonio pero, si se contrae, unas veces lo hará inválido y otras ilícito, como es el que se ha contraído sin la preceptiva dispensa. Para todo ello, se tiene en cuenta el grado del parentesco, más cercano o más remoto, y la línea que media entre los afines, recta o colateral.

Cuestión para especialistas es el caso del matrimonio nulo por haberse contraído con un impedimento dispensable, pero sin haber obtenido la obligatoria dispensa para poder contraerlo válidamente, supuestos en los que sí cabrá convalidarlo ${ }^{1}$ o bien sanarlo en raíz, ${ }^{2}$ siempre que se den los requisitos establecidos en los preceptos del Código Canónico, pero esta es una materia que excede nuestro cometido.

Con esta investigación sobre los efectos de la afinidad en el matrimonio se aporta un material de especial interés sobre la historia religiosa en el mundo y, por tanto, en España y en el mundo hispánico. Desentrañar su alcance a lo largo de la historia de la humanidad nos ha exigido tener que remontarnos a muchos siglos atrás.

\section{DiSPOSICIONES EN LA MÁS REMOTA ANTIGÜEDAD}

La afinidad, relación de un cónyuge con los familiares de su consorte, se encuentra regulada desde el siglo XVI a.e.c., en el Código de Hammurabi (hacia el año 1753 a.e.c.), ${ }^{3}$ en el Código Mesoasirio (entre el 1115 y el 1077

\footnotetext{
${ }^{1}$ Cfr. cánones 1156 a 1160 del Código de Derecho Canónico.

${ }^{2}$ Cfr. cánones 1161 a 1165 del Código de Derecho Canónico.

${ }^{3}$ Deimel, A. 1930. Codex Hammurabi, textus primigenius. Romae: Sumptibus Pontificii Istituti Biblici. Bergmann, E. 1953. Codex Hammurabi: textus primigenius. Roma: Editrice Pontificio Istituto Biblico. Finet, A. 1973. Le Code de Hammurabi. París: Éditions du Cerf. Lara Peinado, F. 1982. Código de Hammurabi. Madrid: Editorial Nacional.

Hispania Sacra, LXIV

129, enero-junio 2012, 97-139, ISSN: 0018-215-X, doi: 10.3989/hs.2012.004
} 
a.e.c. $)^{4}$ y en las Leyes Hititas (sobre el 1460 a.e.c.), ${ }^{5}$ es decir, desde la más remota antigüedad ${ }^{6}$ y también, en las disposiciones del Antiguo Testamento.

\section{Código de Hammurabi (siglo XVI a.e.c.)}

Las uniones entre parientes afines en línea recta son incestuosas:

«Si uno eligió esposa para su hijo y su hijo cohabitó con ella, si después el mismo ha yacido en su seno y la toma, se ligará a ese hombre y se le arrojará al agua» (n. 155).

Si hubo consumación del matrimonio, la sanción a imponer al padre era la muerte; pero la joven quedaba implícitamente absuelta por considerarla incapaz de oponerse a la voluntad del padre.

«Si un hombre eligió esposa para su hijo y su hijo no cohabitó con ella, pero si él ha yacido en su seno, le pagará una media mina de plata y, además, le devolverá todo lo que ella hubiera traído de la casa de su padre; después el hombre de su elección, podrá tomarla» (n. 156).

Media mina es el equivalente a 250 gr. Esa era la sanción para el padre si el matrimonio del hijo aún no se había consumado, quedando la joven implícitamente absuelta por considerarla incapaz de oponerse al deseo del suegro; pero con derecho a recibir esa indemnización pecuniaria pues había quedado devaluada a los ojos del hijo, su esposo.

«Si uno, tras la muerte de su padre, duerme en el seno de su madre, se les quemará a los dos» (n. 157).

«Si uno, después de su padre, ha sido sorprendido en el seno de su «grande», de la cual tuvo hijos, ese hombre será arrancado de la casa paterna» (n. 158).

Esa mujer del padre no es la propia madre.

La expresión «grande», hirtu en acadio, indica a «la primera esposa».

\footnotetext{
${ }^{4}$ Sanmartín, J. 1999. Códigos legales de tradición babilónica: 79-183. Barcelona: Editorial Trotta.

${ }^{5}$ Hrozny, F. 1922. Code Hittite provenant de l'Asie Minuere. París. Neufeld, E. 1951. The Hittite Laws. London: Publication Name: Luzca \& Co.

${ }^{6}$ Freyer, H. y Hertz, F. 1945. El despertar de la Humanidad. Las culturas de los tiempos primitivos. Asia Oriental y Oriente mediterráneo: I, 7-67. Madrid: Espasa Calpe. Molina, M. 2000. La ley más antigua. Textos legales sumerios. Barcelona: Trotta edicions de la Universitat de Barcelona. Pliegos de Oriente. Finkelstein, J. J. 1966. Sex Offenses in Sumerian Laws: 355-372. Jaos. Pritchard, J. B. 1966. La sabiduría del Antiguo Oriente. Barcelona: Garriga.
} 
Leyes Hititas (sobre el 1460 a.e.c.)

El Imperio Hitita está situado en Asia Menor.

Sus leyes fueron descubiertas el año 1906 en la excavación en Boghazköi (Turquía). Es considerado como el primer tratado legal europeo, en lengua indoeuropea, no semítica. Las tablillas de estas leyes, que recogen un texto anterior, son del siglo XVI a.e.c. El ejemplar más importante es de alrededor de 1400 a.e.c.

Fue promulgado con la dinastía que subió al trono hacía el año 1460 a.e.c. Se compone de 200 párrafos y contiene importantes disposiciones sobre uniones entre parientes afines.

«Si un hombre peca con su suegra, no hay escándalo; pero si el padre vive todavía, es una fechoría» (Ley 190).

«Si un hombre libre se acuesta con hermanas libres y su madre, pero con una en un país y con otra en otro, no hay escándalo. Si están dos en el mismo lugar y se sabe su parentesco, es una fechoría» (Ley 191).

«Si la esposa de un hombre muere y éste toma a su hermana, no hay escándalo» (Ley 192).

"Si un hombre tiene mujer y el hombre muere, su guardián legal [hitita: hermano] la tomará como esposa. Si el hombre y el guardián legal mueren, luego la tomará el padre. Pero si muere el hombre, el hermano y el padre, entonces uno de los hijos de su hermano la tomará como mujer y no son acciones dignas de castigo» (Ley 193).

«Si un hombre libre se acuesta con hermanas no libres y su madre, no hay escándalo. Si unos parientes duermen con una misma mujer libre, no hay escándalo. Si un padre y su hijo duermen con una esclava o una prostituta, no hay escándalo» (Ley 194).

«Si un hombre posee sexualmente a la mujer de su hermano mientras su hermano vive, la sentencia será la muerte. Si un hombre tiene como esposa a una mujer libre y posee sexualmente a la hija de ésta, es acción execranda. Si un hombre tiene a una hija como esposa, y posee sexualmente también a la madre o a la hermana de ésta, es acción execranda»(Ley 195).

Código Mesoasirio (entre 1154 y 1077 a.e.c.)

Al gran rey de Asiria, Teglatfalasar I, que reinó de 1115 a 1077 a.e.c. se debe el Código Mesoasirio. Fue encontrado en 1903 por arqueólogos alemanes en Asur, actual Irak.

Sobre el levirato se hallan las siguientes disposiciones:

«Si el marido de una mujer que todavía vive en la casa de su padre muere y ella no tiene hijos, el padre de su marido nombrará a uno de sus hijos como guardián legal de ella (...) o desempeñará él mismo el papel de guardián legal de ella» (31, primera parte).

Hispania Sacra, LXIV

129, enero-junio 2012, 97-139, ISSN: 0018-215-X, doi: 10.3989/hs.2012.004 
Si muere el marido de una mujer que todavía vive en la casa de su padre, y también muere el padre de ella y el padre de su marido, y ella no tiene hijos, entonces ella pasará a ser viuda y podrá ir donde quiera» (33).

\section{La Biblia}

Interesa destacar, en primer lugar, que la Biblia tiene sus propias normas de interpretación ${ }^{7}$ y que en ella encontramos multiplicidad de disposiciones sobre la afinidad en el Antiguo Testamento.

Los especialistas bíblicos datan entre los siglos XVIII al XIII a.e.c. los cinco primeros libros del A.T. En ellos, hallamos prohibiciones, castigos para el infractor, maldiciones y, por el contrario, un mandato expreso que obliga a contraer matrimonio con mujer afín si el hermano ha muerto sin hijos, llamado «el levirato».

\section{a. Prohibiciones}

«Ninguno de vosotros se acercará a una mujer con la que tenga parentesco para descubrir su desnudez. Yo, el Señor» (Lv. 18,6).

«No descubrirás la desnudez de la mujer de tu padre, pues su desnudez es la de tu padre» (Lv. 18,8).

«No descubrirás la desnudez del hermano de tu padre ni te llegarás a su mujer, pues es la mujer de tu tío» (Lv. 18,14).

«No descubrirás la desnudez de tu nuera, pues es la mujer de tu hijo. No descubrirás su desnudez» (Lv. 18,15).

«No descubrirás la desnudez de la mujer de tu hermano, pues su desnudez es la de tu propio hermano» (Lv. 18,16).

«No descubrirás la desnudez de una mujer y la de su hija. Ni tomarás a la hija o al hijo de tu mujer para descubrir su desnudez. Son de su misma carne: es una perversión» (Lv. 18,17).

«No tomarás a una mujer y a su hermana haciéndolas rivales, ni descubrirás su desnudez mientras viva la primera» (Lv. 18,18).

«Todo el que cometa alguna de esas abominaciones será extirpado de en medio de su pueblo» (Lv. 18,29).

«Así, pues, guardad mis disposiciones. No practiquéis ninguna de las abominables costumbres que tenían quienes os precedieron, pues os haríais impuros con ellas. Yo, el Señor, vuestro Dios» (Lv. 18,30).

\footnotetext{
${ }^{7}$ Pontificia Comisión Bíblica. 1993. La interpretación de la Biblia en la Iglesia: III, A, 80. Città del Vaticano: Librería Editrice Vaticana. Spadafora, F. 1963. Dizionario Bíblico: 367. Roma. Juan Pablo II. 2005. Memoria e identidad: 91-92. Madrid: La esfera de los libros.
} 


\section{b. Castigos para el infractor}

Entre parientes afines en línea recta

«Si uno cohabita con la mujer de su padre, ha descubierto la desnudez de su padre; ambos morirán sin remedio: caiga su sangre sobre ellos» (Lv. 20,11).

«Si uno cohabita con su nuera, ambos morirán sin remedio; han cometido una infamia: caiga su sangre sobre ellos» (Lv. 20,12).

«Si uno toma por esposa a una mujer y a la madre de ésta, comete una perversión. Él y ellas serán quemados vivos para evitar que esa perversión se dé entre vosotros» (Lv. $20,14)$.

Entre parientes afines en línea colateral

La unión tenía una pena inferior: carecer de descendencia. Lo que supondría que, si había prole, ésta era ilegítima y esos hijos no podrían inscribirse en las listas genealógicas, sin dejar constancia de su existencia.

«Si uno cohabita con la mujer de un tío suyo, ha descubierto la desnudez de su tío. Cargarán con su iniquidad. Morirán sin hijos» (Lv. 20,20).

«Si uno toma por esposa a la mujer de su hermano comete una ignominia. Ha descubierto la desnudez de su hermano. Quedarán sin hijos» (Lv. 20,21).

En el siglo XVI de la e.c. Enrique VIII, Rey de Inglaterra, pretendió que el Papa declarase nulo su matrimonio con la Reina Catalina, alegando esos textos del Lv. 20,20-21, a pesar de haber obtenido la dispensa pontificia que embargaba ese matrimonio por impedimento de afinidad. No lo consiguió, se produjo el cisma y la Iglesia quedó rota. Por lo que, cinco siglos después, bien puede afirmarse que fue un impedimento matrimonial de afinidad que conmocionó al mundo. Para más información sobre esta interesante materia, que excede nuestro cometido, remito al que le interese a: María Rosa Corazón Corazón. 2007. La afinidad. ISBN: 978-84-669-3033-8. Depósito Legal: M-54932-2007. Tesis Doctorales. Facultad de Derecho. Ciencias Sociales. Servicio de Publicaciones. Universidad Complutense. Madrid, 59-93, 516-525, 531-532 y 630-818. En:

http://www.ucm.es/BUCM/

http://www.ucm.es/BUCM/tesis/der/ucm-t30020.pdf

\section{c. Maldiciones}

«Maldito quien yazca con la mujer de su padre, porque alzaría la cubierta del lecho paterno! Y el pueblo responderá: ¡Amén!»(Dt. 27,20). 27,23).

«Maldito quien yazca con su suegra! Y todo el pueblo responderá: ¡Amén!» (Dt.

Hispania Sacra, LXIV

129, enero-junio 2012, 97-139, ISSN: 0018-215-X, doi: 10.3989/hs.2012.004 


\section{d. El levirato}

«Si varios hermanos viven juntos y uno de ellos muere sin hijos, la mujer del difunto no tendrá que ir fuera para casarse con un extraño: su cuñado irá donde ella, la tomará como esposa y ejercerá así la ley del levirato. El primogénito que dé a luz llevará el nombre del hermano difunto, para que no sea borrado su nombre de Israel» (Dt. 25,5-6).

No cumplir la obligación del levirato suponía para el infractor una gravísima ignominia, que detalla Dt. 25,7-10: denuncia ante los ancianos, en presencia de éstos la mujer le quitará el zapato y le escupirá en el rostro y en Israel su casa será llamada «la casa del descalzo».

La institución del levirato hunde sus raíces en la consanguinidad, pues el hijo lleva en sus venas la sangre de la familia del difunto, que es también la sangre del hombre que lo engendró, pues son hermanos. Se produce así, en el levirato, un punto de encuentro entre la afinidad y la consanguinidad.

El levirato se practicaba entre los judíos desde la época patriarcal. Era una vieja costumbre vigente entre los semitas, asirios e hititas del Asia Menor y entre los árabes del Yemen. ${ }^{8}$

La palabra hermano no significaba hijos de los mismos padres, pues en idiomas antiguos, hebreo, arameo, árabe, etc., no había palabras para indicar los diversos grados de parentesco. En general, todos los pertenecientes a una misma familia, clan, incluso tribu, eran hermanos, que podían indicar otros grados de parentesco, como primos, sobrinos, etc. ${ }^{9}$

\section{DeReCHO ROMANO}

En Roma, existían prohibiciones para el matrimonio tanto por parentesco de sangre o consanguinidad como por afinidad. Esas prohibiciones estaban formuladas en sentido negativo, como actualmente sucede en nuestros Códigos ${ }^{10}$ y se debían a variadas razones de índole ética, política, social o religiosa.

La unión entre afines en grado prohibido, además de no ser un iustum matrimonium, producía graves consecuencias jurídicas pues, al haber cometido los contrayentes crimen de incesto, sus hijos serían considerados ilegítimos, y obligación de restituir la dote recibida.

\footnotetext{
${ }^{8}$ Brown, R. Fitzmyer y J. Murphy, R. 1972. «San Jerónimo», en Comentario Bíblico: I, 334. Madrid: Ediciones Cristiandad.

${ }^{9}$ Arribas Garrido, F. 2002. Aurora de la Salvación: 211. Segovia: Impresión: Taller Imagen (Segovia).

${ }^{10}$ Artículo 46 del Código Civil español: «No pueden contraer matrimonio...». Código Civil. 2000. Madrid: Tecnos.

Artículo 47: «Tampoco pueden contraer matrimonio...».
} 
Asesinar a un pariente afín constituía un delito de parricidio, tal y como consta en el Digesto que la Lex Pompeia de parricidis del año 55 a.e.c., estableció:

«Son reos de parricidio los que alevosamente mataren a su (...) yerno, suegra, padrastro, madrastra o hijastro».

El castigo para tales era ser azotados, encerrados en un saco de cuero con una serpiente, un mono, un gallo y un perro y ser arrojados a lo profundo del mar. ${ }^{11}$ El emperador Adriano, que gobernó del 117 al 138, sustituyó el castigo del saco de cuero por la pena de ser arrojado a las bestias, al fuego. La Constitución Ad Verinem Vicarium Africae, de Constantino, del año 312, demuestra que el suplicio de la Lex Pompeia no había caído en desuso.

En el año 355 las prohibiciones al matrimonio se extendieron al casamiento de una mujer con su cuñado, considerándolo incesto. El cambio afectó a muchos judíos practicantes que aún obedecían los preceptos mosaicos sobre el matrimonio del levirato. Teodosio el Grande, en el año 393, prohibió a los judíos obedecer esos preceptos. ${ }^{12}$

La relación sexual entre un hombre y una mujer antes del matrimonio no generaba afinidad entre ellos y no implicaba un obstáculo para que posteriormente pudieran contraer matrimonio ni siquiera siendo adúltera esa relación prematrimonial. ${ }^{13}$ En el Derecho Romano no se contemplaba lo que posteriormente, en la Edad Media, se denominará cuasi afinidad.

Para que el matrimonio alcanzase plenos efectos civiles era necesario que los contrayentes estuvieran dotados de connubium, que determinaba y reflejaba la recíproca capacidad matrimonial de ambos cónyuges. ${ }^{14}$

En los jurisconsultos de la época imperial encontramos las primeras prohibiciones matrimoniales entre afines. ${ }^{15}$

Gayo, del siglo II a.e.c., con sus Instituciones, su obra más importante, contribuyó a fijar las base para las Instituciones de Justiniano, y recogió la prohibición y su extensión:

\footnotetext{
${ }^{11}$ Digesto I, 1. De lege Pompeia de parricidiis, XLVIII, 9.

${ }^{12}$ Cod. 1.9.7 Brundage 149.

${ }^{13}$ C. I. Diocleciano 9.9.26. Digesto. 48.5.12(11),13. «El matrimonio de los esclavos; estudio histórico-jurídico hasta la fijación en el Derecho Canónico». Analecta Gregoriana, ser B.1, Vol. 23.

${ }^{14}$ Bosch Gimpera, P. 1940. «España Romana (218 a.C a 414 d.C.)», en Menéndez Pidal, R. Historia de España: Tomo II. Madrid: Espasa Calpe. Bannon, C. J. 1997. The brothers of Romulus: fraternal P $i$ etas in Roman law, literature, and society. Princeton, NJ: Princeton University Press. Bonfante, P. 1925. Derecho de Familia. Roma: Atilio Sampaolessi Editore. Vega Gutiérrez, A. M. 1997. La unidad del matrimonio y su tutela penal: precedentes romanos y canónicos del delito de bigamia. Granada: Comares. Lozano Corbí, E. 1994. Sipnosis de Historia e Instituciones de Derecho Romano. Zaragoza: Mira.

${ }^{15}$ Wieacker. 1960. Textstufen klassischer Juristen. Gotinga.
} 
«Tampoco es lícito contraer matrimonio con la tía paterna y materna, o con la que en algún momento fue mi suegra, mi nuera, mi hijastra y mi madrastra. Y decimos en algún momento, porque si perdura todavía el matrimonio del cual resulta tal afinidad, no puede casarse conmigo por otra razón: porque no puede ella estar casada con dos, ni tener yo dos mujeres» (Gayo, Instituta 1,63).

Paulo, de fines del siglo II a.e.c., fue asesor de Papiniano y praefectus praetorio. Sus Sententias sirvieron de base para la Lex Romana Wisigothorum, que las recoge en su Libro IV, el cual lleva por título De origine naturali, y para las Etimologías de San Isidoro. Han llegado a nosotros a través de la Lex Romana Wisigothorum, Digesto, Collatio (Mosaicarum et Romanarum legum collatio), Fragmenta Vaticana, Consultatio veteris cuiusdam iurisconsultati, Lex Romana Burgundiorum y Appendix Lex Romana Wisigothorum.

Paulo trató la afinidad en línea recta, ascendente y descendente y su extensión.

«Veamos ahora qué se entiende por "madrastra", "hijastra", "suegra" y "nuera", para que entendamos con quien no es lícito casarse.

Suele decirse que ni con la "madrastra" que es propiamente la mujer del padre, ni con la "nuera" que es la mujer del hijo, ni con la "hijastra" que es la hija de la mujer nacida de otro marido; pero en el matrimonio, es más cierto que uno no puede casarse con la mujer del abuelo o bisabuelo; en consecuencia las madrastras con las que no debe uno casarse son dos o más; no hay que sorprenderse porque tampoco el hijo adoptivo pueda casarse ni con la mujer del padre natural, ni con la del adoptivo, y si mi padre hubiera tenido sucesivamente varias mujeres, no podré casarme con ninguna de ellas.

Así también con el nombre de "suegra", no solo se entiende la madre de mi mujer, sino hasta la abuela y la bisabuela, de modo que no puedo casarme con ninguna de ellas; también bajo el nombre de "nuera" está comprendida, no sólo la mujer del hijo, sino hasta la del nieto y del biznieto, aunque algunos llaman a estas "pronueras".

Asimismo se entiende por "hijastra", no solo la que es hija de mi mujer sino también la que es nieta y biznieta, de modo que no puedo casarme con ninguna de ellas.

Además Augusto interpretó que no podía casarme con la madre de la que tuve por desposada, pues había sido mi suegra». ${ }^{16}$

El siguiente texto de las Sentencias de Paulo, recogido en el Digesto, determinaba que el límite legal del parentesco llegaba hasta el séptimo grado. Tendrá enorme trascendencia por la aplicación que hizo la Iglesia en la Edad Media.

«En estos siete grados se contienen todos los nombres de los parientes; más allá de los cuales ni se puede encontrar afinidad, ni se puede propagar más la sucesión» (Paulo, Sentencias, Tit. II, Lib. IV, Int. 4,10,8).

«En el séptimo grado, que son los parientes en línea recta hacia arriba y hacia abajo, no se los llama con nombres propios; pero en línea transversal se contienen los quintos nietos y quintas nietas, y los primos hermanos, hijos e hijas de la hermana de la madre» $(4,11,7)$.

\footnotetext{
${ }^{16}$ Paulus. Sententiae II,19,5 y Collatio 6,3,1.
} 
«Por tanto se establecieron siete grados de sucesión, porque más allá y por la misma naturaleza de las cosas, ni se pueden encontrar nombres que designen el parentesco ni se puede propagar a los descendientes en vida» $(4,11,8)$.

Paulo, reconociendo a la afinidad efectos jurídicos tanto para las herencias como para poder ser testigos, dispuso, y así ha quedado recogido en el Digesto, idéntica extensión tanto para deferir herencias como para eximir de la obligación de testificar. Y consta en Coll. 9,3,2, que Paulus, Sententiae [V] sub titulo de testibus et quaestionibus, determinó:

«Los testigos no pueden ser interrogados sin su voluntad contra un pariente afín o contra un pariente cognado».

«El jurisconsulto debe conocer los grados de los parientes y de los afines, porque por las leyes, las herencias y la tutela vuelven al pariente más próximo.

En su edicto, el Pretor da la posesión al pariente más próximo; aparte de que por ley no obligamos en los juicios públicos a dar testimonio contra su voluntad ni a los afines, ni a los parientes». (Digesto, 38,10,10. Paulus, Liber sing. de gradibus et adfinibus et nominibus eorum, pr.).

Que el parentesco llegaba hasta el séptimo grado lo apoya la opinión mayoritaria. No obstante, también hay autores, como Klenze, ${ }^{17}$ Voigt $^{18}$ y Bonfante, ${ }^{19}$ que sostuvieron que el parentesco romano llegaba hasta el sexto grado. Y otros, como Perozzi, ${ }^{20}$ que consideraron que era indefinido. ${ }^{21}$

La opinión mayoritaria estima que la razón de que el parentesco llegara hasta el séptimo o hasta el sexto grado se debe a un error al traducir el siguiente texto en la Interpretatio:

4.10 .8 «In his septem gradibus omnia propinquitatum nomina continentur; ultra quos nec affinitas inveniri nec successio potest amplius propagari» (Paulo, Sentencias, tit. II del lib. IV Int).

Papiniano (140-212), encontramos sus disposiciones sobre la afinidad en Liber IV de Responsa

«No debe la mujer del hijastro casarse con el padrastro, ni el que fue marido de la hijastra casarse con la madrastra» (Papinianus. Liber IV. Responsorum).

También las hallamos en el Digesto:

\footnotetext{
${ }^{17}$ Klenze. 1828. Zeitschrift für geschichliche Rechtswissenchaft: VI, 1-200.

${ }^{18}$ Voigt. Ius naturale: III, 1163.

${ }^{19}$ Bonfante, P. Resmancipi: $1^{\mathrm{a}}, 293$ y 300.

${ }^{20}$ Perozzi, S. 1906. Istituzioni di diritto romano: 7 y 61-91. Firenze: Barbera.

${ }^{21}$ Fernández Espinar, R. 2003. Las prohibiciones de contraer matrimonio entre parientes en la época visigoda: 62, en nota a pie de página. Granada: Gráficas del Sur.

Hispania Sacra, LXIV

129, enero-junio 2012, 97-139, ISSN: 0018-215-X, doi: 10.3989/hs.2012.004
} 
«Si se cometiese adulterio con incesto, por ejemplo con la hijastra, o con la mujer del hijo o con la del padre natural o adoptivo, también será castigada la mujer; lo mismo se entenderá aunque no se verificase el adulterio». (Digesto 48, 5,38: El mismo; Cuestiones, libro XXXVI).

Ulpiano (170-228), define el connubio como «la facultad de tomar esposa jurídicamente»(Ulpiano, Ep. 5,3).

«Se da el matrimonio si entre los que contraen nupcias existe el connubium, siendo el varón púber y la mujer núbil, y consienten ambos si son «sui iuris», o sus padres si están bajo su potestad». (Ulpiano, Ep. 5,2).

«A la que fue madrastra o hijastra, o nuera, o suegra no podemos tomarla como esposa. Si alguien tomara como esposa a la que no le es lícito, contrae matrimonio incestuoso y, por eso, los hijos no se encuentran bajo su potestad, sino que, concebidos ilegítimamente, son como espurios» (Liber regularum singulari, sub título «De nuptiis». En Título VI «De las nupcias incestuosas» de Collatio 6, 2,1).

Discípulo de Ulpiano, Modestino, es autor de obras de las que solo se conservan fragmentos. Su definición del matrimonio la recoge el Digesto:

«Matrimonio es la unión del marido y la mujer en consorcio de toda la vida, comunión de derecho divino y humano». (Digesto 23,3,1)

Consta en Fragmenta Vaticana 218 y 302 que Modestino encontró en el matrimonio el fundamento de la afinidad, tal y como recoge el Digesto:

«Pero porque también hay algunos derechos entre los parientes por afinidad, no es ajeno tratar aquí de ellos sucintamente.

Afines se llaman los parientes del marido y de la mujer, se llaman así porque dos parentelas diversas entre sí se unen por el matrimonio y una de ellas se enlaza con un extremo de la otra; en efecto, la causa de contraerse la afinidad es el matrimonio.

Sus nombres son: suegro, suegra, yerno, nuera, madrastra, padrastro, hijastro, hijastra» (Digesto 38,11,4,3-4).

Junto a los jurisconsultos, los Códices nos transmiten la regulación de la afinidad.

Codex Gregorianus, a. 196-295, atribuido a un jurista desconocido del tiempo de Diocleciano. ${ }^{22}$ Debió ser un texto muy amplio, pues el título «De nuptiis» contenía al menos treinta y dos Constituciones.

Castigaba gravemente las uniones incestuosas y contiene disposiciones sobre la afinidad.

\footnotetext{
${ }^{22}$ Iglesias, J. 1965. Derecho Romano. Instituciones de Derecho Privado: 53 y 56. Barcelona: Ediciones Ariel. Wieacker. Ibídem. 93 y ss.
} 
Del Codex Hermogenianus, a. 291-365, no se conservan sus originales. Conocemos sus disposiciones a través de la Collatio Mosaicarum, la Consultatio veteris, las Papiniani responsa, los Fragmenta Vaticana, la Lex Romana Wisigothorum $^{23}$ y la Lex Romana Burgundionum. ${ }^{24}$ Extraído de Collatio y bajo el título de nupcias, este Codex sancionó las uniones con pariente afín.

Ambos Códigos recogieron los principios sancionados durante el Bajo Imperio por los Emperadores Diocleciano (245-313) y Maximiano (250-310). En ambos hay prohibiciones para contraer nupcias entre parientes afines en línea recta. $^{25}$

No obstante, consta que las incumplió Caracalla al contraer matrimonio con Julia, la segunda esposa de su padre, el emperador Septimio Severo.

Él dijo: «Querría, si me fuera lícito».

A lo cual le respondió Julia:

«Si te place, te es lícito. ¿O es que no sabes que eres emperador, y no estás sometido a las leyes?». ${ }^{26}$

El Codex Theodosianus, a. 438 y 439, tiene carácter oficial y se debe a Teodosio II. Fue el primero que trató ordenadamente las prohibiciones para contraer matrimonio por razón de parentesco, apreciando ya un cierto paralelismo entre el Derecho Civil y el Derecho de la Iglesia. Recogió Constituciones imperiales de los emperadores romano-cristianos a partir del año 311 y fue promulgado como Ley para Oriente el 15 de febrero de 438 y para Occidente en el año 439, hasta que en Oriente fue sustituido por las Compilaciones Justinianeas. Su extracto se recogió en la Lex Romana Wisigothorum. ${ }^{27}$

Una disposición de Constantino, inserta en el Código Teodosiano, ${ }^{28}$ prohibió tomar por esposa a la hija del hermano. ${ }^{29}$

En el 393 se prohibió contraer a los cuñados ${ }^{30}$ extendiendo la prohibición de

${ }^{23}$ N.a: Lex Romana Wisigothorum recoge las Sentencias de Paulo, en ocasiones seguidas de un comentario que interpreta su sentido, lo que se conoce con el nombre de Interpretatio.

${ }^{24}$ N.a: Lex Romana Burgundionum es Appendix Lex Romana Wisigothorum.

${ }^{25}$ Cod. I, 17, De nuptiis, v. 4.

${ }^{26}$ Spartien. Vie d'Antonin Caracalla: 10.

${ }^{27}$ Mommsen, T. 1905. Theodosianus Codex et Novellae. Berolini: Ed. Th. Mommsen et P. Meyer. Meyer, P. M. 1905. Theodosiani, libri XVI cum Constitutionibus Sirmondianis et Leges Novellae ad Theodosianum pertinentes. Berolini: Ed. Th. Mommsen et Meyer, P. Godefroy, J. 1665 y 1736-1745 Codex Theodosianus cum perpetuis commentariis J. Gothofredi... Pramittuntur chronologia accuratior, cum chronico historico, et prolegomena... opus posthumum... recognitum... opera et studio A. Marvillii. 6 tom. Lugduni. Other editions: Lipsiæ.

${ }^{28}$ C. Th. 1.2 De incest nupt.

${ }^{29}$ C. Th. $3,12,1$.

${ }^{30}$ C. Th. $3,12,2$. C. $5,5,5$.

Hispania Sacra, LXIV

129, enero-junio 2012, 97-139, ISSN: 0018-215-X, doi: 10.3989/hs.2012.004 
la época clásica para el matrimonio entre afines en línea recta, ${ }^{31}$ pero sin anular los matrimonios ya contraídos. ${ }^{32}$

Justiniano (482-565), emperador entre los años 527 y 565. Su obra, conocida desde el siglo XII por Corpus Iuris Civilis, comprende el Codex, Institutiones, Digesto o Pandectas y Novelas (Nuevas Leyes). ${ }^{33}$

El Corpus Iuris Civilis es la fuente primordial para el Derecho Romano. Recoge sistemáticamente lo que ya, de algún modo, se había iniciado en los tres Códigos anteriores: Codex Gregorianus, Hermogenianus y Theodosianus.

Codex Iustinianeus, 4 de abril de 529, compiló Constituciones imperiales junto con opiniones de jurisconsultos. Prohibió contraer nupcias con afines en línea recta y con consanguíneos en línea recta y colateral:

«A nadie le está permitido contraer matrimonio con la hija, nieta, biznieta, madre, abuela, bisabuela, ni colaterales, tía paterna, tía materna, hermana, hija de hermana, ni de sobrina, ni de las afines, hijastra, madrastra, nuera, suegra, ni las demás que se prohíben en el derecho antiguo, de todas las cuales debemos abstenernos». ${ }^{34}$

Instituta, 21 de noviembre de 533, Libro I, Título X: de las nupcias, prohíbe el matrimonio con afín en línea recta:

«Por respeto de la afinidad es también necesario abstenerse de ciertas nupcias. Así, no es lícito casarse con la hijastra ó con la nuera porque una y otra ocupan el lugar de hijas.

Lo que debe entenderse así, también en el caso de que lo hayan sido, pues si todavía fuere tu nuera, es decir si aún estuviere casada con tu hijo, no podrás tomarla por mujer por otra razón, a saber, que no puede estar casada la misma mujer con dos a un tiempo; $y$ del mismo modo si aún fuere hijastra tuya, esto es, si su madre estuviere casada contigo, por idéntica razón tampoco podrás tomarla por esposa, porque no te es lícito tener al mismo tiempo dos mujeres». (Instituciones I,10,6).

«Está igualmente prohibido casarse con la suegra o con la madrastra, porque se hallan en el lugar de madre. Lo que también procede después de disuelta la afinidad; pues en otro caso, si aún es tu madrastra, esto es si todavía está casada con tu padre, por el derecho común te está prohibido casarte con ella, porque una misma mujer no puede hallarse casada con dos a la vez; y de igual manera, si aún es tu suegra, esto es, si su hija está todavía casada contigo, también son imposibles las nupcias porque no puedes tener dos mujeres simultáneamente». (Instituciones I,10,7).

\footnotetext{
${ }^{31}$ Gayo, 1,63. Digesto. 12,7,5,1. Digesto. 23,2,14,4.

${ }^{32}$ C. Th. 23 y 26.

${ }^{33}$ Justiniano. Codex. Institvtiones. Digestum o Pandectae: http://www.gmu.edu/departments/fld/ CLASSICS/justinian.html

${ }^{34}$ Codex V,4,17. Impp. Diocletianus et Maximianus A.A. et C.C. D. k. Mai. Damasco Tusco et Anullino, Cons. y Collatio, VI,4,5.
} 
«Sin embargo, el hijo del marido y de otra mujer, y la hija de la mujer y de otro marido, o viceversa, pueden lícitamente contraer matrimonio aún cuando tengan hermano o hermana nacidos después del segundo matrimonio». (Instituciones I,10,8).

«Si después del divorcio tu mujer hubiera procreado de otro una hija, ésta no es ciertamente tu hijastra, pero Juliano dice que deben evitarse estas nupcias; porque, aunque ni la esposa del hijo es nuera, ni la esposa del padre es madrastra, habrán obrado, sin embargo, mejor y en derecho los que se hubieren abstenido de semejantes nupcias». (Instituciones I,10,9).

«Hay además otras personas que no pueden contraer matrimonio por diversas razones que, recogidas del derecho antiguo, nos hemos permitido enumerar en los libros del Digesto o Pandectas». (Instituciones I,10,11).

«Si contraviniendo lo prescrito, algunos se unieren, entiéndase que no hay ni marido, ni mujer, ni nupcias, ni matrimonio, ni dote. Así pues los que de este coito nacen no están bajo la potestad del padre; sino que son (en cuanto a la patria potestad respecta), tales como los que la madre concibió del vulgo. Pues se entiende que estos no tienen padre, siendo éste incierto o desconocido; de donde suelen ser llamados hijos espurios, según la voz griega, ó como hijos sin padre. Síguese de aquí que, disuelta tal unión, ni a la exacción de la dote hay lugar. Además, los que contraen nupcias prohibidas sufren asimismo otras penas que en las constituciones imperiales se contienen». (Instituciones I,10,12).

Digestum o Pandectae, 15 de diciembre de 533, Libro 23, Título II, trata sobre la debida forma del matrimonio, prohibiéndolo entre afines:

«No puedo contraer matrimonio con la desposada de mi padre, aunque no sea propiamente mi madrastra.

Tampoco podrá mi desposada casarse con mi padre, aunque no pueda decirse que es propiamente su nuera.

Si mi mujer, después del divorcio se casa con otro y tiene de él una hija, estima Juliano que ciertamente ésta no es hijastra mía, pero que debo abstenerme de contraer matrimonio con ella. ${ }^{35}$

\section{Esta prohibición era mucho más rigurosa en línea recta que en línea colateral:}

«Papiniano en el Libro IV responde: «No debe la mujer del hijastro casarse con el padrastro, ni el que fue marido de la hijastra casarse con la madrastra»». ${ }^{36}$

«Responde Aristón que del mismo modo que se prohíbe el matrimonio con la hijastra, se prohíbe también con la hija de ésta». ${ }^{37}$

"Por derecho de gentes comete incesto el que se casa con la que está en línea ascendente o descendente; pero el que se hubiese casado con una colateral en grado prohibido, ó con la pariente por afinidad con que se le impide el matrimonio, se le castigará levemente si lo hace abiertamente, y con más rigor si lo hace clandestinamente. La razón de la diferencia está en que respecto al matrimonio que no se debe contraer con colateral, los infractores públicos se excusan de la pena mayor como a causa de error, y los que obran clandestinamente son castigados como contumaces». ${ }^{38}$

${ }^{35}$ Digesto 23,2,12,1,2 y 3 Ulpianus Liber XXVI ad Sabinum.

${ }^{36}$ Digesto 23,2,15 Papinianus Liber IV Responsorum.

${ }^{37}$ Digesto 23,2,40 Pomponius Liber IV ex Plautio.

${ }^{38}$ Digesto 23,2,68 Paulus, Liber singulari ad Senatusconsultum Turpillianum.

Hispania Sacra, LXIV

129, enero-junio 2012, 97-139, ISSN: 0018-215-X, doi: 10.3989/hs.2012.004 
La infracción de las prohibiciones que impedían el matrimonio por razón de parentesco constituía crimen de incesto:

«Si alguno se casa con alguna de las que se nos prohíbe por costumbre, se dice que comete incesto». (Digesto 23,12,39).

«Si se comete adulterio con incesto, por ejemplo con la hijastra, la nuera o la madrastra, la mujer será igualmente castigada, pues lo sería aunque no fuera por el adulterio». (Digesto 48,5,38: Idem liber XXXVI. Quaestionum).

Consta en Digesto 38,11 que la extensión del parentesco llegó hasta el séptimo grado, pero también se menciona el sexto grado:

Gayo; Comentario al Edicto provincial, libro VIII.

«Están en sexto grado de ascendientes el quinto abuelo y quinta abuela, de los descendientes el quinto nieto y quinta nieta; y en la colateral el cuarto nieto y nieta del hermano y hermana... sado...

En el séptimo grado están todas las personas que ya se pueden deducir de lo expre-

Los nombres de los afines son los siguientes: suegro, suegra, yerno, nuera, madrastra, padrastro, hijastro e hijastra...

Así, pues, no es lícito contraer matrimonio entre los que están como ascendientes o descendientes a causa de afinidad...»

Nacimiento y extinción en Roma de la prohibición para las nupcias por razón de afinidad

Mommsen señala que la relación de parentesco entre suegro y nuera, yerno y suegra, padrastros e hijastros, por lo mismo que es producida por el matrimonio y se asemeja a la que existe entre padres e hijos, se convierte, mientras subsista el matrimonio de donde la afinidad proviene, en circunstancia agravante de las relaciones sexuales, porque añade al adulterio el incesto. Y aún después de disuelto el matrimonio, esas relaciones seguirán siendo incestuosas. ${ }^{39}$

Una de las cuestiones más discutida por los jurisconsultos de la época imperial fue la causa que originaba la afinidad. Fue opinión general que la afinidad nacía de las iustas nupcias. Si bien, también hay constancia documental ${ }^{40}$ de que a los esponsales ${ }^{41}$ se les atribuyó parentesco de afinidad.

Así, por un lado se halla recogido en Fragmenta Vaticana que la afinidad continúa aún después de disueltas las justas nupcias:

\footnotetext{
${ }^{39}$ Mommsen, T. 1999. Derecho Penal Romano: 157. Pamplona: Analecta Editorial. Traducción Pedro Dorado Montero.

${ }^{40}$ Fragmenta Vaticana. Filippi, M de. 1998. Fragmenta Vaticana: storia di un testo normativo. Bari: Cacucci, cop.

${ }^{41}$ N.a. Esponsales es promesa de matrimonio.
} 
«Asimismo. Por otra parte en la Ley Papia se mencionan como afines aquellos que en algún tiempo fueron marido y mujer, yerno y nuera, suegro y suegra. Y también el padrastro, la madrastra, el hijastro, la hijastra, de ellos mismos o de quienes estén o hubieren estado bajo su potestad o en su matrimonio». (Fragm. Vatic. 218 y 219).

Y este texto, por sus palabras «aquellos que en algún tiempo fueron...»y «de quienes estén o hubieren estado...», parece dar a entender que la afinidad no se acaba al extinguirse el matrimonio del que procede. Pues siendo la afinidad figura unida de modo inseparable al matrimonio, se le atribuyen efectos perdurables en el tiempo, juzgando que permanecía vigente la afinidad tras ser disuelto el matrimonio.

No obstante, y sirva para poner de manifiesto la confusión que reinaba sobre ello, dan a entender justamente lo contrario los siguientes textos de Fragmenta Vaticana:

«Asimismo. Pero en ésta los que son afines en el momento de la donación se incluyen, y lo mismo contestó por rescripto el divino Pío; pues las leyes, en efecto, que hubieran querido incluir también a aquellos que lo habían sido con anterioridad, lo habrían dispuesto expresamente». (Fragm. Vatic. 303).

Este texto parece indicar justamente lo contrario por sus palabras «afines en el momento...» y en otro caso «lo habrían dispuesto expresamente».

Pudiendo concluirse de todo lo anterior que no existía afinidad por razón de esponsales, sino que eran más bien razones de carácter ético las que desaconsejaban que un padre se casara con la mujer que había destinado para su hijo y viceversa.

\section{Cristianización del Derecho Romano}

El progresivo reconocimiento del cristianismo llevó a su declaración como religión oficial ${ }^{42}$ Empezó desde entonces a acentuarse una disparidad de criterios sobre la prohibición para contraer matrimonio por razón de afinidad.

Las uniones de esta clase eran incesto a los ojos del cristianismo, como se puede apreciar en los Concilios de Elvira (306) y de Neocesarea (314).

Los Emperadores cristianos fueron animados por la Iglesia a recoger en el Derecho positivo esa prohibición religiosa. ${ }^{43}$ Los cánones de los Concilios de Elvira y de Neocesarea influyeron en la legislación civil romana de ese tiempo

\footnotetext{
${ }^{42}$ Bonfante, P. 1946. Istituzioni di Diritto Romano. Milano. Biondi, B. 1952-1954. Il Diritto Romano Cristiano. Milano.

${ }^{43}$ Troplong, M. 1843. De l'influençe du christianisme sur le droit civil des Romains. París. Montemayor Aceves, M. E. 1994. Comparación de leyes mosaicas y romanas. México.
} 
y esa influencia se hizo notar en la legislación imperial de Teodosio el Grande. Éste, en el 355 y a petición del Papa Liberio, dictó una Constitución para Oriente y Occidente, que proscribía el matrimonio entre afines en línea colateral. ${ }^{44}$

Con Constantino se prohibió el matrimonio entre cuñados en una Constitución, recogida en el Código Teodosiano, Código 1.2 De incest nupt., pero sin anular los matrimonios ya contraídos (Código Teodosiano, Libro 23 y 26).

El Código Teodosiano 3,12,2, que recoge una Constitución del año 335 de Constancio y Constante, extendió la prohibición al matrimonio entre cuñados. Estas prohibiciones por parentesco de afinidad fueron confirmadas por Valentiniano, Teodosio y Arcadio. ${ }^{45}$

La Constitución de Constancio, dada en Antioquia el año 342, prohibió el matrimonio entre consanguíneos y pronto se extendió a los demás parentescos. Zenón reprodujo la prohibición de Constancio y calificó tales uniones de «turpissimum consortium, nefandissimum scelus, contagium». ${ }^{46}$ Justiniano, en Codex I.V,5,9 y V,8,2 recogió la prohibición, citando las Constituciones anteriores.

Pero estas disposiciones no dieron fin a los matrimonios entre cuñados. Así, consta que el emperador Honorio se casó con dos hermanas, primero en el año 398 con su prima María, hija de Stilicón y, sin haber consumado ese matrimonio, se casó posteriormente en el año 408 con Thermantia. Pero, además, todo esto no impidió que, siete años más tarde, renovase la prohibición para el matrimonio entre cuñados. ${ }^{47}$

\section{LA AFINIDAD EN LA EDAD MEDIA}

Trataron sobre la afinidad los Padres de la Iglesia. ${ }^{48}$

De los de la Iglesia Griega, sólo San Basilio el Grande (330-379) ${ }^{49}$ recogió disposiciones sobre el parentesco de afinidad.

\footnotetext{
${ }^{44}$ Godefroy, D. 1726. «Commentaire sur le Code Thèodosien» en Corpus Iuris Civilis Romani: I, 337 y ss. Amberes. Gradenwitz. 1925. Heidelberger Index zum Theodosianus. Berlín y Gradenwitz. 1929. Ergänzungsband zum Theodosianus. Berlín.

${ }^{45}$ Ortolán, M. 1873. Explicación histórica de las Instituciones del Emperador Justiniano precedida de la Historia de la Legislación Romana. Madrid: Librería de D. Leocadio lópez, editor.

${ }^{46}$ Fernández Espinar, R. 2003. Ibídem: 36-37.

${ }^{47}$ Tillemont, L. de. 1720. Histoire des empereurs et des autres princes qui ont regné durant les six premiers siecles de l'Eglise. París: Chez Charles Robustel.

${ }^{48}$ Coll. $74 \mathrm{~T}=$ Diuersorum patrum sententiae, siue Collectio in LXXI titulos digesta. Ciudad del Vaticano, 1973.

${ }^{49}$ Migne, J. P. 1857-1866. Patrologiae cursus completus. Series graeca. PG. París. Basilius, San. 1929. Tomus 29-32. Obras ascéticas de San Basilio (traducción por A. Sheptyckyj). Lviv. Quasten, J. 1977. Patrología 2. Madrid, n. 217, pp. 224-260.
} 
En Occidente, sólo San Agustín y San Gregorio Magno escribieron sobre la repercusión del parentesco en el matrimonio.

San Agustín (354-430) se mostró partidario de que se eligiera al cónyuge fuera de la parentela. Su doctrina sobre el matrimonio quedó expuesta en sus obras de carácter moral y ascético, "Contra Fausto el Maniqueo», «Del bien del matrimonio», «De los enlaces adulterinos», «Sobre el matrimonio y la concupiscencia», «De civitate Dei», y brevemente, en «Qvaestionvm in Heptatevchvm», libri VII.

En «Contra Fausto el maniqueo», año 398, afirma que Judas durmió con su nuera:

«Más grave hubiera sido que con su nuera durmiese conscientemente, pues siendo una misma carne el marido y la mujer, debe estimarse la nuera igual que la hija». (Contra Faustum manich., libri triginta tres).

En «De Civitate Dei», con un nuevo y audaz texto y refiriéndose al desarrollo de la moral sexual en la historia, afirmó que los hijos varones de Adán y Eva se tuvieron que casar con sus mismas hermanas, a fin de propagar la especie, dado que era la primera generación. Mas cuando ya hubo suficientes mujeres para casarse, se prohibió ese incesto entre hermano y hermana, permitiéndose el matrimonio entre primos; posteriormente y con el paso del tiempo, aún esos matrimonios entre parientes cercanos llegaron también a ser ilícitos. Lo justifica.

Las obras de San Gregorio Magno (540-604) son un amplísimo epistolario, admirables homilías, un famoso Comentario al Libro de Job, escritos sobre la vida de San Benito, numerosos textos litúrgicos, célebres a causa de la reforma del canto que por su nombre fue llamado «gregoriano».

Su obra más famosa «Regla pastoral», ${ }^{50}$ del año 591, es una colección de textos extraídos de 200 epístolas. En ella afirma:

«Comete incesto quien se une a una consanguínea suya y a la que, bajo la línea de afinidad, tuvo un consanguíneo suyo.

Ningún fiel tome, pues, esposa hasta la séptima generación ni en la línea de la afinidad, ni consanguínea suya, para no contaminarse de algún modo con la mancha del incesto. Pues del incesto dice Teodoro en su Penitencial:

"Si alguno teniendo esposa comprometida llevase su pecado a la hermana de ésta y tomase después como mujer a la que se había desposado, y la que había sufrido su pecado se ahorcase, que todos los que participaron en el desarrollo de este hecho sean obligados a diez años de penitencia" ${ }_{.5}^{51}$

\footnotetext{
${ }^{50}$ Gregorio Magno, San. MCMLVIII. Obras. Madrid.

${ }^{51}$ Gregor der Grosse. 1995. Von der Sehnsucht der Kirche. Freiburg.
} 
No obstante las dispensas concedidas a los anglos por estar recién llegados a la fe, San Gregorio extendió los impedimentos de consanguinidad y de afinidad hasta el séptimo grado inclusive..$^{52}$

De entre las muchas e importantes obras que escribió San Isidoro de Sevilla (560-636), destacan Orígenes o Las Etimologías ${ }^{53}$ El complicado cómputo de los grados del parentesco en los impedimentos matrimoniales adquirió una enorme importancia y enorme complejidad a lo largo de la Edad Media. San Isidoro lo estudió detenidamente y en sus Etimologías, Libro IX, canon VI, 29 llevó el parentesco y, con él, el impedimento de consanguinidad hasta el sexto grado. No obstante, la prohibición para el matrimonio se llevó hasta el séptimo grado $^{54}$ en la Europa Medieval, incluso a través de San Isidoro de Sevilla, de la Hispana y del Liber Iudiciorum.

\section{Los primeros concilios y sínodos}

En el comienzo del siglo IV se encuentran las primeras disposiciones conciliares ${ }^{55}$ sobre las consecuencias jurídicas de matrimonios entre parientes afines; pero en ningún momento se utilizó el término impedimento sino prohibición para contraer matrimonio. ${ }^{56}$ La noción de impedimento matrimonial aparecerá, posteriormente, con el desarrollo del Derecho Canónico.

En los siglos IV y V, las relaciones con la hermana de la novia se consideraban incestuosas y obligaban a penitencia. No obstante, no parece que el matrimonio estuviera prohibido entre el adúltero y su cómplice, de uno u otro sexo, tras la disolución del primer matrimonio. Las prohibiciones matrimoniales por

\footnotetext{
${ }^{52}$ Can. De affinitate 35, quaest. 2, can. Nullum; can. Progenium; can. De consanguinitate; can. Nulli ibid.

${ }^{53}$ Lindsay, W. M. 1911. Etymologiarum sive Originum libri, XX. Oxford.

${ }^{54}$ N.a: Ya hemos hablado del motivo de la confusión sobre si el parentesco llegaba hasta el sexto o hasta el séptimo grado se debió a un error en la traducción de la Interpretatio del texto que consta en las Sentencias de Paulo (4.10.8), que consideraba que a efectos sucesorios el parentesco llegaba hasta el séptimo grado, pero fue mal traducido. Por ello, para unos llega hasta el sexto y para otros hasta el séptimo.

${ }^{55}$ Hefele, K. J. von y Leclercq, H. 1907-1921. Histoire des Conciles d'après les documents originaux. París: Letouzey, 9 vol. Fernández y Larrea, R. 1788 y 1827. Synodorum oecumenicarum summa, in qua praeter uniuscuiusque concilii historicam enarrationem, in médium etiam afferuntur canones universi, atque scholiis quibusdam elucidantur. Editio altera, novis curis elaborata, correctior \& adaucta ad usum verspertinae canonum cathedrae per... Raymundum Fernández \& Larrea. Vallisoleti. Apud viduam et filios. Santander y Typ. León Amarita. Matriti.

${ }^{56}$ Casas, Bartolomé de las. 1869. Summa conciliorum omnia tam generalium quam provincialium; collecta dum agere in Concilio Tridentino. Marietti. Martínez Díez, G. 1984 y 1992. La colección canónica hispana. Concilios hispanos. Concilios galos. Madrid. González, F. A. Tejada y Ramiro, J. 1849-55. Colección de cánones y de todos los concilios de la Iglesia española. Madrid. Tomo I, 44-46. MGH. Epist. 3, 482-485. Suberbiola Martínez, J. 1987. Nuevos concilios hispano romanos de los siglos III y IV. La colección de Elvira. Málaga. Gaudemet, J. 1993. El matrimonio en occidente. Madrid.
} 
razón de parentesco, alianza o relaciones fuera del matrimonio empezaron a esbozarse y experimentaron posteriormente un notable desarrollo.

Los Concilios de esta época legislaron sobre los parentescos y las prohibiciones para contraer matrimonio por razón de ellos. Pero trataron más el parentesco de consanguinidad que el de afinidad, mencionándolo sólo aisladamente y en ocasiones.

a. Concilio de Elvira, a. 306, se celebró en Guadix, en la iglesia Eliberitana, durante el reinado de Constantino y bajo el pontificado de San Dionisio.

Reviste particular importancia, pues sirvió de pauta para la legislación conciliar posterior. ${ }^{57}$ Dispuso sobre la afinidad:

«Canon 61: De aquellos que se casan con dos hermanas. Si alguien después de la muerte de su mujer se casare con la hermana de aquella y ésta fuere cristiana, tenemos por bien que se abstenga de la comunión durante cinco años. A no ser que una grave enfermedad obligase a administrársela antes». (Concilium Eliberritanum, LXI).

La exigencia es mayor que en la legislación romana, donde sí estaba permitido el matrimonio con la hermana de la mujer difunta.

«Canon 66: De aquellos que se casan con sus hijastras. Si alguno se casare con su hijastra, por ser un incestuoso tenemos por bien no se le dé la comunión, ni aún a la hora de la muerte». (Concilium Eliberritanum LXVI).

El Concilio de Elvira es el primer Concilio que recogió la prohibición para el matrimonio por razón de afinidad, no sólo en línea recta en su canon 66, sino también en línea colateral en el canon 61. Dispuso sanciones de distinta gravedad para el caso de incumplimiento de sus disposiciones. La afinidad en línea recta llevaba aparejada una de las mayores penas: la excomunión perpetua, pues se consideró una deshonestidad. La afinidad en línea colateral llevaba consigo una sanción menor: la excomunión durante cinco años, en ese caso, la pena impuesta sí permitía al infractor reconciliarse con la Iglesia tras dicho periodo.

b. Concilio de Neocesarea, año 314, dispuso:

«Canon 2: La mujer que se hubiere casado con dos hermanos quede excomulgada hasta su muerte. Pero usando de benignidad se le concederán los sacramentos en su última hora, con la condición de que si se restableciese sea admitida a la comunión disuelto el matrimonio. Pero si la mujer muriese subsistiendo este matrimonio, será difícil

${ }^{57}$ Códice antiguo Vigilano, ms. D.I.2, de El Escorial, en letra visigótica, ff. 133-137. Monumenta Germaniae Histórica. Berlín, 1916. Vives, J. MCMLXIII. Concilios visigóticos e hispano-romanos. Barcelona-Madrid, 12-13. Vives, J. Marín, T. y Martínez, G. 1963. Concilios visigóticos e hispanoamericanos. Barcelona-Madrid, 2-15. Gómez Morán, L. 1951. Teoría de los Impedimentos para el Matrimonio. Madrid, 17.

Hispania Sacra, LXIV

129, enero-junio 2012, 97-139, ISSN: 0018-215-X, doi: 10.3989/hs.2012.004 
la penitencia al cónyuge sobreviviente, cuya sentencia obligará con la misma igualdad a los hombres que a las mujeres».

Y conforme a esa disposición, la Carta canónica de San Basilio a Amphilochio $^{58}$ prohibió admitir a la participación de los Sacramentos al que se hubiere casado con la viuda de su hermano, si antes no se separaba. ${ }^{59}$ Hay, pues, pena de excomunión y la separación de los cónyuges en caso de matrimonio entre el hermano del cónyuge fallecido y la esposa de éste.

c. Sínodo Romano, a. 402, celebrado bajo el Pontificado de Inocencio I, en sus cánones 9 y 11 prohibió el matrimonio con la hermana de la difunta esposa y con la viuda del tío.

\section{d. Concilio de Toledo II, a. 527}

Determinó que no se podía contraer matrimonio por personas entre las que podía haber derecho de sucesión; es decir, prohibió el matrimonio entre parientes hasta el séptimo grado. Y tal disposición del Concilio de Toledo II del año 527 quedó recogida en el Decreto de Graciano: Decretum, c.35, q.8, c.2.

Las normas conciliares tuvieron repercusión en la legislación civil, como se puede apreciar en la Lex Romana Wisigothorum y en el Liber Iudiciorum.

Hay que reseñar que el concepto de impedimento como causa que impide un matrimonio y puede dar lugar a la nulidad del mismo ex initio se desconoce en esta primera época. La noción de nulidad del vínculo matrimonial exige un fino sentido jurídico capaz de distinguir entre la situación de hecho: se ha celebrado la boda, y la realidad jurídica o estado de derecho: ab initio no ha existido ese matrimonio por haberse infringido una grave prohibición que no admite dispensa.

Así, muchos años más tarde, el Papa San Zacarías, (741-752), en su carta Gaudio Magno del 5 de enero de 747, dirigida a Pipino y a los obispos de Francia, recogió la disposición del canon 2 del Concilio de Neocesarea, concluyendo:

«Nos, pues, con la ayuda de la gracia de Dios y de conformidad con los decretos de nuestros antecesores los pontífices que nos han precedido -confirmándolos todavía másdecimos que no se celebren matrimonios según el rito y la norma de la religión cristiana y romana hasta tanto no se conozca el parentesco. $Y$-lo que no suceda-que tampoco se atreva ninguno a tomar por mujer a la comadre (...); es, en efecto, algo ilícito y pecaminoso delante de Dios y de sus ángeles. Es un pecado tan grande que nada se ha dicho al

\footnotetext{
${ }^{58}$ Basilio, San. 1964. Carta canónica de San Basilio a Amphilochio en Cartas elegidas de San Basilio el Grande, (traducción S. Fedyniak). New York. Pitra. 1864-1868. Iuris Ecclesiastici Graecorum historia et monumenta. Romae, $2 \mathrm{t}$.

${ }^{59}$ Canon 23 Carta canónica de San Basilio a Amphilochio. Fedwick, P. J. 1979. Basil of Caesarea Christian, Humanist, Ascetic. Canadá: Pontifical Institute of Mediaeval Studies.
} 
respecto ni por los santos padres ni en las disposiciones de los sagrados concilios o en las leyes imperiales; prefirieron callar, por temor al juicio de Dios». ${ }^{60}$

En el inicio del Derecho matrimonial de la Iglesia se hallan disposiciones de emperadores romanos y doctrinas de jurisconsultos romanos ya bautizados, junto con disposiciones conciliares y respuestas dadas por los Papas a cuestiones que les planteaban, Decretales y otras aportaciones teológicas y jurídicas.

Los primeros textos con un cierto carácter legal, como los Breves, dirigidos a un grupo y emanados de la autoridad, son los cánones de los concilios, que dieron el nombre de Derecho Canónico al Derecho de la Iglesia y son la fuente legislativa más importante de los siglos IV y V.

Hasta entonces, la Iglesia, haciendo suyas las normas del Levítico y Deuteronomio y las del Derecho Romano, consideró que la afinidad provenía del matrimonio válido, no de la cópula, y el impedimento sólo surgía en la línea recta.

Desde comienzos del siglo IV la afinidad se computó hasta el primer grado de la línea colateral. Y, a partir de entonces, se fue extendiendo progresivamente hasta tal punto que a finales del siglo VII la afinidad llegó hasta el $7^{\circ}$ grado de la computación canónica, con igual extensión que la consanguinidad.

Sobre el proceso penitencial de la Iglesia visigoda hay que decir que no difiere del observado durante la última época de la dominación romana. El pecador, reo de gravísimos crímenes, era primero excomulgado y después, una vez que se acogía a la penitencia, pasaba a formar parte del grupo de penitentes, donde con vigilias, ayunos, oraciones y limosnas trabajaba para expiar sus culpas. Terminado el tiempo de la satisfacción, era reconciliado de nuevo con la Iglesia y admitido a la comunión eucarística. ${ }^{61}$

Por exceder nuestro cometido, no es posible tratar ahora sobre las disposiciones conciliares y sinodales de la España visigoda, Galia merovingia y época carolingia, con su influencia en las leyes civiles respectivas, por lo que remitimos al interesado a la obra de mayor envergadura: María Rosa Corazón Corazón. 2007. La afinidad. ISBN: 978-84-669-3033-8. Depósito Legal: M-54932-2007. Tesis Doctorales. Facultad de Derecho. Ciencias Sociales. Servicio de Publicaciones. Universidad Complutense. Madrid, 143-172, 273-364 y 365-384. En:

http://www.ucm.es/BUCM/

http://www.ucm.es/BUCM/tesis/der/ucm-t30020.pdf

${ }^{60}$ MGH. Epist. 3, 482-485.

${ }^{61}$ González Rivas, S. S. J. 1949. La penitencia en la primitiva Iglesia española. Salamanca. 


\section{LA AFINIDAD EN LAS ANTIGUAS LEYES CIVILES}

La legislación conciliar fue recogida en la Capitular de Carlo Magno del año 743. Esas prohibiciones se introdujeron en otro documento de fecha incierta, posteriormente reproducido por el mismo Carlomagno en el año $768,{ }^{62}$ con el mismo criterio que ya había seguido su padre, Pipino el Breve, y mantuvo después el emperador carolingio y rey de Italia, Luis II, años 855 a 875 . Este mismo criterio consta también en las Leyes de Alamanes, ${ }^{63}$ de Bávaros ${ }^{64}$ y de los Burgondeses. ${ }^{65}$ Se recogió en el Edicto de Teodorico, ${ }^{66}$ en la Lex Wisigothorum, en el Edicto de Rothario y en las Leyes de Luitprando. ${ }^{67}$

Así, Rothario, Rey de los Longobardos, ordenó que:

«Nadie tome por mujer a la viuda de su primo carnal y tampoco a la viuda de su tío carnal. Y esto hemos enseñado porque el Papa nos ha exhortado para que así lo hiciésemos». ${ }^{68}$

La entrada de los germanos en el territorio del Imperio determinó su convivencia con la población de tradición jurídica romana, produciéndose una progresiva fusión entre estos dos grupos y dando lugar a nuevos conceptos en materia matrimonial.

Durante un tiempo, la Iglesia no reclamó para sí tener competencia exclusiva sobre el Matrimonio de los cristianos, sino que la compartió con el poder civil. Cuestión que sí reivindicó y asumió como propia en los siglos posteriores. ${ }^{69}$ El matrimonio de los cristianos recibió gran influencia del Derecho Romano. No debe extrañar, pues, que el Derecho Romano sea fuente principal del ordenamiento jurídico español y, en él, de la regulación sobre el matrimonio; pero también recibió influencia del matrimonio judío, del griego y del germánico. ${ }^{70}$

A partir del siglo IV, al bautizarse los emperadores romanos, la influencia fue recíproca.

\footnotetext{
${ }^{62}$ Lex Salica a Carlo Magno emendata anno 768 (XIV, De ingenuis hominibus qui ingenuas mulieres rapiunt, 16).

${ }^{63}$ Lex Alamannorum, XXXIX, De illicitis nuptiis, 1-2. «De los matrimonios ilícitos». Alamanos, grupo suevo del sur de Germania.

${ }^{64}$ Lex Bajuvariorum, tit. VI, cap. I. De nuptiis incestis prohibendis. «De los prohibidos matrimonios incestuosos».

${ }^{65}$ Tit. XXXVI.

${ }^{66}$ Cap. XXXVI.

${ }^{67} \mathrm{Lib}$. III, tít. V, cap. I y 13.

${ }^{68}$ Legum Longobardarum, Lib. II, Tít. 8, 4. y Rotharius, 185.

${ }^{69}$ Ritzer, K. 1970. Le mariage dans les Églises chrétiennes du Ier au XI siècle. París: Cerf.

${ }^{70}$ Castán Tobeñas, J. 1976-87. Derecho Civil Español, Común y Foral. Madrid: Reus S.A. Tomo I, Volumen I, 190-199.
} 
Desde el siglo VI hubo una gran preocupación por las uniones incestuosas, siendo una de las primeras y principales inquietudes de los Concilios.

Poco a poco se formó una doctrina cada vez más precisa ${ }^{71}$ sobre conceptos y efectos de los impedimentos matrimoniales, sometiendo su lista, cada vez más larga, a una consideración unitaria. E incluso se puso en la escuela varias veces, para ayudar a la memoria, como puede verse en la glosa al Decretum. ${ }^{72}$ Se puso en forma métrica en la Summa Aurea o Summa Ostiense de Henricus de Segusio, Cardinalis Ostiensis, conocido como el Hostiense, del siguiente modo:

«Error, conditio, votum, cognatio, crimen, cultum, disparitas, vis, ordo, ligamen, honestitas, dissensus, et affinis, si forte coire nequibis, haec facienda vetant connubi, facta retractant.»

A partir del siglo XI, y durante un largo periodo, la Iglesia fue la única que legisló sobre el matrimonio, haciéndolo mediante cánones conciliares, decretales pontificias y estatutos de sínodos diocesanos. En la mayor parte de los casos, recogían la legislación general; pero, a veces, adelantándose a ella.

En los siglos XI y XII las colecciones canónicas dedicaron importantes disposiciones a regular el matrimonio. Se continuó con el Decreto de Graciano ${ }^{73}$ y las colecciones de Decretales.

Conforme a las normas del Levítico y Deuteronomio y a las del Derecho Romano, en los primeros siglos de su historia, la Iglesia consideró que la afinidad provenía del matrimonio válido, no de la cópula, y que el impedimento de afinidad sólo surgía en línea recta. A comienzos del siglo IV se extendió al primer grado de la línea colateral. Y a finales del siglo VII la afinidad se amplió hasta coincidir con la consanguinidad, llegando hasta el séptimo grado de la computación canónica.

En el siglo IX, el origen de la afinidad radicaba en la cópula y no en el válido matrimonio y la cópula ilícita también generaba afinidad, puesto que si el matrimonio hace de dos una sola carne, igual sucede con la cópula ilícita.

La Iglesia afirmó que el matrimonio de los bautizados es uno de los siete sacramentos y que fue instituido por Jesucristo. Su doctrina y predicación sobre el matrimonio se apoya en el poder de las llaves (Jn. 20,22-23) y en el mandato de evangelizar (Mc. 16,15).

\footnotetext{
${ }^{71}$ Ghirlanda, G. 1992. El derecho en la Iglesia misterio de comunión. Madrid: Ediciones Paulinas. Ibán Iván, C. 2004. Manual de Derecho Eclesiástico. Madrid: Trotta.

${ }^{72}$ Decretum. C.XXVII, q. I.

${ }^{73}$ Graciano. Decreto. Extraído de Monumenta Germaniae Historica. Edition Friedberg 1879. N. a: en todo caso, hoy por hoy, la Edición de Friedberg continúa siendo el punto de partida ineludible para la investigación sobre el Decreto de Graciano.

Hispania Sacra, LXIV

129, enero-junio 2012, 97-139, ISSN: 0018-215-X, doi: 10.3989/hs.2012.004
} 
En los años finales de este periodo aumentaron las rupturas matrimoniales basadas en la existencia de algún impedimento por razón parentesco, no dispensado. Era un pretexto. Cuando la unión resultaba demasiado incómoda para alguno de los contrayentes, éste buscaba remotos vínculos familiares para solicitar la nulidad.

Felipe Augusto escribió al Papa, pues se extrañaba de no obtener la disolución de su matrimonio por parentesco. Y alegaba los precedentes de Federico Barbarroja -que había repudiado a Adela de Vohburgo-, y de Juan sin Tierra -que repudió a Isabel de Gloucester-, y hasta de su mismo padre, Luis VII, cuyo matrimonio con Leonor de Aquitania había sido anulado ${ }^{74}$ por el Concilio de Beaugency. Los obispos, reunidos bajo la presidencia del tío del rey, fallaron el divorcio $^{75}$ alegando lazos de parentesco entre Felipe e Ingeburga. ${ }^{76}$

A mediados del siglo XI, Foulques Richin, conde de Anjou, llegó a tener hasta cinco esposas, dos de ellas repudiadas por parentesco. ${ }^{77}$ Roberto de Courçon, -Cardenal y Legado Pontificio del Papa Inocencio III-, deploraba la frecuencia de los falsos testimonios que permitían esos abusos, criticando enérgicamente la dispensa que concedió el Papa al matrimonio de Leonor de Aquitania y Enrique II, pariente suyo. Ese matrimonio fue una de las causas del conflicto entre Francia e Inglaterra. Opinaba que las dispensas solo debían otorgarse en caso de necesidad y por evidente utilidad, y que en ese caso fue inútil. ${ }^{78}$

Pedro el Chantre, muerto en 1197, criticó que las normas se usaran para obtener una ruptura y que se aplicaran criterios diferentes para iguales casos de parentesco. ${ }^{79}$

\footnotetext{
${ }^{74}$ N.a: Hay que distinguir entre anular -declarar que ahora ya no vale lo que antes era válido- $y$ declarar nulo ab initio. El matrimonio, si es válido, no puede anularse porque es indisoluble. Cuando se declara nulo por el Tribunal competente es porque ha resultado probado, con toda la certeza moral posible, que no existió desde su inicio por ausencia de algo que era esencial para que se pudiera contraer. Para mayor información: Corazón, R. 2001 y 2003. Nulidades matrimoniales... que no lo separe el hombre. $3^{\circ}$ edición. Bilbao: Desclée de Brouwer y $4^{\mathrm{a}}$ edición en: www.autorescatolicos.org (Laicos. Rosa Corazón). Corazón, R. 2003. Cásate y verás. Madrid: Marova.

${ }^{75} \mathrm{~N}$. a: Una declaración de nulidad de un matrimonio es algo totalmente distinto de un divorcio o de una anulación. Se trata de términos jurídicos precisos y distintos entre sí. Pero vemos que en algunas traducciones, como esta, no se usa con la necesaria precisión jurídica el sentido propio y genuino de cada uno de esos términos jurídicos.

${ }^{76}$ Brugiere, M. B. 1979. Le mariage de Philippe Auguste et d'Isambour de Danemark. Toulouse : Mél Dauvillier.

${ }^{77}$ Duby, G. 1977. Le mariage dans la société du haut Moyen Áge. «Il matrimonio nell'alto Medioevo». I. Settimane di Studio del Centro Italiano di Studi sull'Alto Medioevo. Spolète (Italy) c.i.s.a.m., 13-39. Repris dans Duby, 1988, 11-33.

${ }^{78}$ Summa 27,11, BN lat. 14524, f. 96. Aldwin, J. W. 1963 y 1965 «Critics of the Legal Profession Proceed» of the $2^{\text {nd }}$. Intern. Congress of Medieval Canon Law. Boston y Roma.

${ }^{79}$ Verbum abbreviatum, (PL, 205, 474). N.a: Algunos de estos casos actualmente podrían considerarse una exclusión de la indisolubilidad.
} 


\section{LAS COLECCIONES CANÓNICAS}

En el siglo XII llegaron a formar un arsenal de material patrístico, conciliar y pontifical. Sus disposiciones tenían como fin establecer normas para cortar los numerosos abusos. Fueron escasos, por este motivo, los estudios dogmáticos y doctrinales.

Por otro lado, nos encontramos en plena reforma eclesiástica, con una gran preocupación por el incesto. Los canonistas de este periodo insistieron en que la relación sexual en el matrimonio y fuera de él, creaba una afinidad matrimonial.

El nuevo Derecho, elaborado por concilios y Papas, unas veces completó y otras modificó el anterior; quedando todo ello recogido en las colecciones canónicas. En todas, el matrimonio fue objeto de atención preferente. Los textos de los Concilios provinciales entraron pronto en las colecciones, pasando de unas a otras, hasta desembocar en el Decreto de Graciano. Hay que destacar, además del Decreto de Graciano, el Decreto de Burchardo (1008-1012), ${ }^{80}$ la obra de Ivo de Chartres (1040-1116), con su famosa Colección Tripartita: Decretum, Panormia ${ }^{81}$ y Epístolas, a Hugo de San Victor (1096?-1141) con su obra De sacramentis, ${ }^{82}$ considerada como la primera gran exposición sobre el matrimonio.

\section{LA AFINIDAD EN GRACIANO}

El Decretum de Graciano es una de las más importantes colecciones de Derecho Canónico. Aparecida poco antes de mediados del siglo XII, compila el Derecho Canónico de los once primeros siglos, con una vasta síntesis del Derecho común de la Iglesia, y reúne cerca de tres mil quinientos textos pontificios, conciliares, patrísticos y escriturísticos.

Desde mediados del siglo XII será utilizado de modo habitual in scholis et in iudicis. ${ }^{83}$

\footnotetext{
${ }^{80}$ Burchardo. Decreto. Extraído de Patrología Latina. Database [Recurso electrónico]. Migne. París.

${ }^{81}$ Ivo, San. 1557. Pannormia seu Decretum D. Ivonis Carnothensis Episcopi restitutum. Lovanii, excudebat Stephanus Valerius, expensis Antonii Maria Bergaingne.

${ }^{82}$ San Victor, Hugo de. 1485. De sacramentis christianae fidei. PL, T. 176, y Typ. Jordani: «Sermones» (H. 9438), Strasbourg, Libro II. Parte 11, cap. XIV y XV.

${ }^{83}$ Corpus Iuris Canonici. MDCCCLXXIX. Editio Lipsiensis Secunda post Aemilii Ludouici Richteri curas ad Librorum Manu Scriptorum et Editionis Romanae Fidem Recognouit et Adnotatione Critica instruxit Aemilius Friedbergs, pars prior Decretum Magistri Gratiani. Ex Officina Bernhardi Tauchnitz. Lipsiae. Kuttner, S. 1984. «Research on Gratian: Acta et Agenda». Proccedings of the Seventh International Congress of Medieval Canon Law. Cambridge. Ferrari, G. C. 1877. Summa Institutionum Canonicorum. Genuae: Typ. Archiepiscopali. Capello, F. M. 1945. Summa Iuris Canonici: in usum scholarum: concinnata. Roma. Winroth, A. The making of Gratian's Decretum. Cambridge, 2000,
} 
Graciano se propuso lograr la unidad interna, la homogeneidad entre todos esos diversos textos. Por ello, su primer título fue Concordia discordantium canonum.

Para Graciano, la afinidad la generaba el coito, no el matrimonio y era perpetua.

\section{OTROS AUTORES QUE TAMBIÉN TRATARON SOBRE LA AFINIDAD}

Hincmaro de Reims (806-882), Jonás de Orleáns (contemporáneo de Hincmaro), Pedro Lombardo (1100-1160) con sus Sentencias, Bernardo de Pavía (i-1213) con Summa Decretalium, San Raimundo de Peñafort (1180-1275) con Summa de Matrimonio, Santo Tomás de Aquino (1225-1274) con Summa Theologica ${ }^{84}$ y otros, son importantes autores que también trataron sobre la afinidad.

Romanos Pontífices como Alejandro III (1100-1181), Inocencio III (11601216) con sus Decretales, Gregorio IX (1170-1241) con sus Decretales, Inocencio IV (?-1254), Clemente V (?-1314) con sus Clementinas y otros Santos Padres, dieron disposiciones sobre el parentesco de afinidad y su influencia en el matrimonio. ${ }^{85}$

\section{CONCILIO ECUMÉNICO DE LETRÁN O LATERANENSE IV, AÑo 1215}

Lo convocó Inocencio III $^{86}$ y fue el más importante de los Concilios medievales ${ }^{87} \mathrm{~A}$ la vista de los muchos y graves inconvenientes surgidos por la enorme

monografía cuyo núcleo central fue su tesis doctoral en la Universidad de Columbia: The Making of Gratian's Decretum. (Columbia University 1996. University Microfilms Inc. [UMI], Ann Arbor-Michigan, 9706925) y «The two recensions of Gratian's Decretum». Xth International Congress of Medieval Canon Law de 1996 en Syracuse (New York), Ius Ecclesiae 9 (1997): 221-264.

${ }^{84}$ Aquino, Tomás de. Santo. 1852. Summa Theologica. Parmae: Typ. Petri Fiaccadori.

${ }^{85}$ Cfr. María Rosa Corazón Corazón. 2007. La afinidad. ISBN: 978-84-669-3033-8. Depósito Legal: M-54932-2007. Tesis Doctorales. Facultad de Derecho. Ciencias Sociales. Servicio de Publicaciones. Universidad Complutense. Madrid, 173201, 202-229, 230-272, 275-364 y 837-926. En:

http://www.ucm.es/BUCM/

http://www.ucm.es/BUCM/tesis/der/ucm-t30020.pdf

${ }^{86}$ Jaffé, Ph. 882-1198. Regesta Pontificum Romanorum. Ed. S. Löwenfeld. Kaltenbrunner, F. (?590) y Ewald, P. (590-882). 1885-1888. Leipzig Veit, reed. Graz. 1956. Verlagsanstalt: Akademische Druck-u. Alberigo, G. 1993. Historia de los Concilios Ecuménicos. Salamanca: Sígueme.

${ }^{87}$ Mansi, J. D. 1901-1927 y 1960. Sacrorum Conciliorum Nova et Amplissima Collectio. Parisiis: Akademische Druck-U y Graz-Austria: Verlagsanstalt. Casas, Bartolomé de las. 1872. Summa conciliorum omnium ordinata. Pariis: editio recens opera ac studio M. L. Bail. Publicación: Fredericus Leonard. García y García, A. 1981. Constitutiones Concilii quarti Lateranensis una cum commentariis glossatorum. Città del Vaticano. 
extensión dada al parentesco para impedir el matrimonio, acordó el Decreto 50 del IV Concilio de Letrán: ${ }^{88}$

«No podría calificarse de reprensible el hecho de que los decretos humanos estén sometidos a variación según la diversidad de los tiempos, especialmente cuando una necesidad imperiosa y evidente así lo exige; Dios mismo ha modificado en el Nuevo Testamento algunas de las leyes que había dictado en el Antiguo.

La prohibición para el matrimonio en el segundo o tercer género de afinidad y la de vincular los hijos del segundo matrimonio al parentesco del primer marido suscitan numerosas dificultades y causan a veces peligros para las almas. Abolida la prohibición, cesa el efecto de la misma. Así pues, con la aprobación del santo Concilio, revocamos los decretos promulgados a este respecto y, por la presente Constitución, establecemos la libertad de celebrar en el futuro tales matrimonios incluidos en los citados grados de afinidad.

En adelante, el impedimento del matrimonio no excederá el cuarto grado de consanguinidad y afinidad; efectivamente, más allá de este límite no se puede mantener la prohibición en general sin graves inconvenientes.

El número cuatro conviene perfectamente al impedimento de unión corporal de la que dice el apóstol: «Porque la mujer no es dueña de su cuerpo sino que lo es el marido. Y así mismo, el marido no es dueño de su cuerpo sino que lo es la mujer» (I Cor. 7,4), pues hay cuatro humores en el cuerpo que provienen de los cuatro elementos.

Una vez establecido para lo sucesivo el impedimento del matrimonio en el cuarto grado, pretendemos que tenga valor universal, a pesar de las constituciones ya promulgadas a este respecto, bien sea por otros, bien sea por Nos mismo. Quienes violando este impedimento contrajeran matrimonio, no podrán invocar en su defensa el paso de los años, puesto que el tiempo, lejos de disminuir el pecado, lo aumenta; la falta es tanto más grave cuanto más tiempo retiene en sus redes al alma desgraciada».

De este modo, la afinidad se redujo del séptimo al cuarto grado. Por lo que, siendo susceptible de variación es, por tanto, de derecho humano y no divino. Se mantuvieron las líneas recta y colateral y los grados primero al cuarto y, a partir de entonces, ya no se contemplarían los géneros, los que surgían de un subsiguiente matrimonio y vinculaban con parentesco de afinidad a los hijos del primer matrimonio con el segundo marido.

\section{Su REFLEJO EN LA HISTORIA RELIGIOSA DE ESPAÑA}

Las disposiciones del Concilio tuvieron su fiel reflejo en la legislación civil española. Así,

El Fuero Real ${ }^{89}$ de 1215 estableció:

\footnotetext{
${ }^{88}$ Monumenta Iuris Canonici. 1965. Ciudad del Vaticano: Biblioteca Apostólica Vaticana, [varias impresiones]. Monumenta Germaniae Historica. 1828, 1879 y 1916. Hahn, varias impresiones, Hannover: Edition Friedbergs y Berlin: Editada por Deutschen Akademie der Wissenschaften.

${ }^{89}$ Fuero Real. Leyes de Alfonso X. 2. Fuero Real. Edición y análisis crítico por Martínez Díez, G. con la colaboración de Ruiz Asencio, J. M. y Hernández Alonso, C. 1988. Ávila.
}

Hispania Sacra, LXIV

129, enero-junio 2012, 97-139, ISSN: 0018-215-X, doi: 10.3989/hs.2012.004 
«Ninguno non sea osado de casar con su parienta nin con su cuñada fasta el grado que manda la santa iglesia, nin de yacer con ella, e qui contra esto ficiere a sabiendas, el casamiento non vala, e ellos sean metidos en seños monesterios para facer penitencia por siempre. Et si uno lo sopiere e el otro non, el que lo sopiere aya la pena. Pero si alguno dellos pudier ganar del rey merced, pueda salir del monesterio al tiempo que el rey mandare». $(4.8,1)$.

«Si alguno yoguiere con muger de su padre, faganle como a traydor, e si yoguiere con la barragana, faganle como alevoso; e si yoguiere con la muger de su ermano, o con su barragana, o con aquella que supiere que su padre o su ermano ha yacido, é si el padre yoguiere con la muger del fijo, o con su barragana, el rey depuse que lo supiere echelos de la tierra por siempre: e sus bienes hayanlos sus herederos, e nunca sean partes de otros, ni puedan testiguar en ningun pleyto». $(4.8,3)$.

\section{Las Partidas, ${ }^{90}$ del año 1265 , regularon la afinidad en varias disposiciones:}

«E cuñadez es allegança de personas que viene del ayuntamiento del varon e de la muger. E non nasce della otro parentesco ninguno. E esta cuñadez nasce del ayuntamiento del varon e de la muger tan solamente, quier sean casados o non, ca maguer algunos fuessen desposados, o casados non nasceria cuñadez dellos amenos de se ayuntar carnalmente. E antiguamente fueron tres maneras de cuñadez e guardaron las en algund tiempo. Mas agora no manda santa Eglesia guardar mas de la primera. E esta es como quando alguno se ayunta carnalmente con alguna muger quier sea casado con ella o non. Ca por tal allegança como esta todos los parientes della se fazen cuñados de la muger cada uno dellos en aquel grado en que son parientes». (Partida IV.2.12 y 6.5).

«Parentesco e cuñadia fasta el quarto grado es la quarta cosa que embarga el casamiento que se non faga e si fuere fecho deuenlo desfacer». (Partida IV, 12).

«Afinidad según Derecho Canónico es: "proximidad de personas proveniente de ayuntamiento carnal, careciendo de toda parentela. Se dice afinidad o casi unidad de dos a un fin, porque dos diversas familias se reunen en ella por desposorio segun las leyes, o por coito segun los canones. La afinidad es un impedimento perpetuo que dura aun después de muerta la persona por la que se contrajo. Por la union carnal de la mujer y del marido los consanguineos del uno contraen con el otro afinidad de primer genero, $y$ del grado mismo que el de consanguinidad; de modo que un pariente consanguineo del marido, distara de la mujer de este tantos grados de afinidad cuantos sean de consanguinidad que diste de dicho su pariente. Entre los consanguineos del marido y de la mujer ninguna afinidad hay, ni tampoco entre los mismos marido y mujer, pues estos son solo causa de ella»». (Partida IV, Título 6, Ley 2).

«Según el Derecho Civil, los grados se encuentran de una manera, y segun el Canonico de otra, porque aquel computa acerca de las sucesiones, y este acerca del matrimonio: el primero cuenta los hermanos en segundo grado distintos entre si, los nietos en quarto, y los bisnietos en sexto; pero segun el Canonico, los hermanos estan en primer grado, los nietos en segundo, y los bisnietos en tercero, y asi se ha de decir en las lineas transversales; pero en los ascendientes y descendientes uno y otro Derecho concuerdan. Por la primera computacion el grado connumeracion de personas singulares, conjuntas por cognacion o afinidad: la raiz de que tuvieron principio señala el grado que la una dista de la otra. Segun la otra computacion, se llama el grado enumeracion de personas,

${ }^{90}$ Partidas. Las siete Partidas del sabio Rey don Alonso el nono, nueuamente glosadas por el licenciado Gregorio López... 1555. Salamanca. 
conjuntas por agnacion o afinidad, las quales descienden de una propia raiz por lineas separadas». (Partida IV, Título 6, Ley 3).

"Affinitas en latin es lo mismo que cuñadez, cuyo parentesco se contrae con la conjuncion del varon y de la muger, ya sean o no casados, sin que nazca de ello otro parentesco; a causa de que la copula carnal hace al varon afin de los consanguineos de la muger en el mismo grado en que se hallan con ella por consanguinidad y lo propio sucede en los consanguineos del varon respecto a la muger, y muerto uno de los conjuntos, el sobreviviente no puede casarse con los consanguineos del difunto que esten dentro del quarto grado». (Partida IV, Título 6, Ley 5).

«Los primos-hermanos y demas parientes que se han expresado no deben casarse hasta el cuarto grado, pero de los otros embargos, que sobrevienen en los casamientos por razon de cuñadez, se entiende en los casamientos que se hacen entre los Christianos. Mas si fueren moros o Judios, si casasen segun su ley con parientes o cuñados, y despues se vuelven Christianos, no se deshace el matrimonio». (Partida IV, Título 6, Ley 6).

"Incesto es pecado que es fecho contra castidad, e cae en este pecado el que yaze a sabiendas con su pariente fasta el cuarto grado o con cuñada que fuesse muger de su pariente fasta en esse mesmo grado. Este pecado ofende mucho a Dios y es considerado como un gran mal». (Partida VII, Título 18, Ley 2).

«El hombre que cometa pecado de lujuria a sabiendas, con parienta o cuñada que no sea su muger, habra la pena de adulterio. Entiendase lo mismo respecto de la muger que cometa este pecado. El que sin dispensa del Papa se case y una carnalmente con tal parienta o cuñada, si fuese hombre distinguido perdera la honra y el puesto que ocupe, y sera desterrado para siempre a una isla; y si no tuviese hijos legitimos de otro matrimonio, perdera todos sus bienes que seran parte de la Camara del Rey». (Partida VII, Título 18, Ley 3).

Caso de notable interés sobre la historia religiosa de España es el del matrimonio de Carlos María Isidro de Borbón con María Teresa de Braganza, princesa de Beira, celebrado el 2 de febrero de 1838, con dispensa pontificia de los impedimentos segundo de consanguinidad y primero con segundo de afinidad, mediante apoderado al efecto, estando presente la esposa y representado el esposo, en la ciudad de Salzburgo (Austria) y en secreto. Para más información ver: María Rosa Corazón Corazón. 2007. La afinidad. ISBN: 978-84-669-3033-8. Depósito Legal: M-54932-2007. Tesis Doctorales. Facultad de Derecho. Ciencias Sociales. Servicio de Publicaciones. Universidad Complutense. Madrid, 513-515, 530, 819-835 y 819-835. En:

http://www.ucm.es/BUCM/ http://www.ucm.es/BUCM/tesis/der/ucm-t30020.pdf

\section{Concilio de TRENTO}

Convocado por el Romano Pontífice Paulo III, ${ }^{91}$ es el más largo de la historia de la Iglesia. Sus sesiones se iniciaron en 1545 y concluyeron en 1563.

\footnotetext{
${ }^{91}$ El Sacrosanto y Ecuménico Concilio de Trento, traducido al idioma castellano por Don Ignacio López de Ayala. Agrégase el texto latino corregido según la edición auténtica de Roma, publicada

Hispania Sacra, LXIV

129, enero-junio 2012, 97-139, ISSN: 0018-215-X, doi: 10.3989/hs.2012.004
} 
Se celebró en tres periodos, ${ }^{92}$ los dos últimos bajo el Pontificado de Julio III y de Pío IV, pues en los pontificados de Marcelo II y Paulo IV no hubo actividad conciliar.

En la tercera fase del Concilio, Sesión XXIV, se trató sobre el matrimonio, la unidad y la indisolubilidad del mismo y el derecho de la Iglesia a fijar los impedimentos matrimoniales. ${ }^{93}$ En esta Sesión XXIV se aprobó la Doctrina sobre el Sacramento del Matrimonio y el Decreto de Reforma, ${ }^{94}$ determinándose: ${ }^{95}$

«Si alguno dijere que sólo aquellos grados de consanguinidad y afinidad, que se expresan en el Levítico, pueden impedir contraer el Matrimonio, y dirimir el contraído, y que no puede la Iglesia dispensar en algunos de ellos, o establecer que otros muchos impidan y diriman; sea excomulgado». (Concilii Tridentini Sessio XXIV. De Sacramento Matrimonii. Canon III)

«Si alguno dijere que la Iglesia no puede establecer impedimentos dirimentes del Matrimonio, o que erró en establecerlos; sea excomulgado». (Concilii Tridentini Sessio XXIV. De Sacramento Matrimonii. Canon IV)

«Si alguno dijere que las causas matrimoniales no pertenecen a los jueces eclesiásticos; sea excomulgado». (Concilii Tridentini Sessio XXIV. De Sacramento Matrimonii. Canon XII).

\section{El Decreto Tametsi ordenó: ${ }^{96}$}

"Quien contrajere Matrimonio de otro modo que en presencia del párroco y de dos o tres testigos, lo contrae inválidamente». (Concilii Tridentini Sessio XXIV. Decretum de Reformatione Matrimonii. Caput I).

«Restríngese al segundo grado la afinidad contraída por fornicación. Además de esto, el santo Concilio, movido por éstas y otras gravísimas causas, restringe el impedimento que nace de la afinidad contraída por fornicación y que dirime el Matrimonio que después se celebra, a sólo aquellas personas que son parientes en primer y segundo grado. Respecto a los grados ulteriores establece que esta afinidad no dirime el matrimo-

en 1564. Quinta edición. Madrid, 1817, 293-352. Canones et Decreta Concilii Tridentini ex Editione Romana a. MDCCCXXXIV. S. Congr. Card. Conc. Trid. Interpretum Declarationes ac Resolutiones ex ipso Resolutionum Thesauro Bullario Romano et Benedicti XIV s.p. operibus et Constitutiones Pontificiae Recentiores ad Ius Commune Spectantes e Bullario Romano Selectae. Lipsiae, 1853, 214-391. Monumenta Germaniae Historica. Ídem. Rosset, M. 1895-1896. De sacramento matrimonii. Tractatus dogmaticus, moralis, liturgicus et iudiciarius. S. Joannis Maurianae, apud acturorem.

${ }^{92}$ Machuca, A. 1903. Los Sacrosantos Ecuménicos Concilios de Trento y Vaticano. Madrid: Librería católica de D. Gregorio Pérez del Amo.

${ }^{93}$ Jedin, H. 1965. El Concilio de Trento en su última etapa. Crisis y conclusión. Barcelona: Editorial Herder, 127-142. Jedin, H. 1975. Historia del Concilio de Trento. Navarra: Eunsa.

${ }^{94}$ Concilio de Trento. Ver: El Sacramento del matrimonio. Sesión XXIV. En: http://www.multimedios.org/docs/d000436/p000011.htm\#h1

${ }^{95}$ Monumenta Iuris Canonici. Ídem. Monumenta Germaniae Historica. Ibídem. Concilia. Legum sectio III.

${ }^{96}$ Monumenta Iuris Canonici. Ídem. Monumenta Germaniae Historica. Ibídem. Concilia. Legum sectio III. 
nio que se contrae después». (Concilii Tridentini Sessio XXIV. Decretum de reformatione Matrimonii. Caput IV).

«Ninguno contraiga Matrimonio dentro de los grados prohibidos; y en qué casos se ha de dispensar en ellos.

Si alguno se atreviere a contraer a sabiendas Matrimonio dentro de los grados prohibidos, sea separado de él y sin esperanza de conseguir dispensa; y esto se ha de aplicar con más rigor respecto del que se atreviese no sólo a contraer Matrimonio, sino también a consumarle. $Y$ si hubiera hecho esto por ignorancia, puesto que se tomó a desprecio las solemnidades que se requieren para contraer Matrimonio, quede sujeto a las mismas penas, por no ser digno de obtener fácilmente la benignidad de la Iglesia quien temerariamente despreció sus saludables preceptos.

Mas si, observadas todas las solemnidades, se supiese después haber oculto algún impedimento, del que probablemente estaba ignorante el contrayente, en este caso se podrá dispensar de él más fácilmente y de gracia.

No se conceda de ningún modo dispensas para contraer Matrimonio o concédanse rara vez, y esto con causa y gratuitamente. Ni tampoco se dispense en segundo grado, a no ser entre grandes Príncipes y por causa pública». (Concilii Tridentini Sessio XXIV. Decretum de reformatione Matrimonii. Caput V).

La Bula de San Pio V Ad Romanum, y los Decretos de la S. Congregación aplicaron este segundo grado que no admitía dispensa, no sólo a la afinidad contraída por matrimonio sino también a la contraída por esponsales (promesa firme y recíproca de matrimonio).

Poco a poco, en todo el mundo católico, aunque con algunas dificultades en España y Francia, se fueron acatando todas las resoluciones de este Concilio que, a lo largo de la historia se ha significado como uno de los más importantes. El concilio tridentino marcó un hito especial en la historia de la Iglesia e, incluso, en la historia universal. ${ }^{97}$

\section{Influencia del Concilio de Trento en la historia Religiosa De España}

Las disposiciones del Concilio de Trento tuvieron fiel reflejo en la legislación civil española hasta 1870. De ello hay clara constancia en la Real Cédula de 27 de octubre de 1563, expedida por el príncipe Don Felipe en ausencia de su padre, en la Provisión del Consejo de 6 de diciembre de 1563, en la publicación en el año 1564 por Felipe II de los Breves que contenían los Decretos de Trento, en la Real Pragmática de Felipe II, Rey de España, mandando observar el Sacrosanto Concilio de Trento por Real Cédula de 12 de julio de $1564,{ }^{98}$ en la Real Cédula de 4 de septiembre de 1564 y en el Real Decreto de 9 de marzo de 1724.

\footnotetext{
${ }^{97}$ Miscelánea conmemorativa del Concilio de Trento (1563-1963). 1965. Estudios y documentos. Consejo Superior de Investigaciones Científicas. Instituto Enrique Flórez. Madrid-Barcelona, 25.

${ }^{98}$ Real Cédula dada por Felipe II en Madrid a 12 de julio de 1564, en Novísima Recopilación, Libro I, Titulo I, Ley XIII. García-Villoslada, R. MCMLXXX. Historia de la Iglesia en España. Ma- 
De todo ello, cabe concluir que las disposiciones del Concilio de Trento estuvieron vigentes en España hasta la Ley de Matrimonio Civil de 18 de junio de 1870 .

\section{LA AFINIDAD ACTUAL, EN LOS TRES CÓDIGOS DE DERECHO CANÓNICO DE LA IGLESIA CATÓLICA 99}

Para la Iglesia Católica latina fue el Código de Derecho Canónico de 1917 y, en vigor, el de 1983.

Corpus Iuris Canonici de 1917 o Pío-Benedictino, ${ }^{100}$ recoge los efectos de la afinidad en el matrimonio en los siguientes cánones:

«La afinidad se origina del matrimonio válido, sea contraído solamente, sea contraído y consumado.

Existe solamente entre el marido y los consanguíneos de la mujer, y asimismo entre la mujer y los consanguíneos del marido.

Se cuenta de manera que los consanguíneos del marido sean, también en la misma línea y grado, afines de la mujer, y viceversa». (Canon 97).

«Fuera del Romano Pontífice, nadie puede abrogar o derogar los impedimentos de derecho eclesiástico, ya sean impedientes, ya dirimentes; ni tampoco dispensarlos, a no ser que por derecho común o por indulto especial de la Sede Apostólica se le haya concedido esta facultad». (Canon 1040).

«Los impedimentos son unos de grado menor y otros de grado mayor. $\$ 2$. Son impedimentos de grado menor: (...) $2^{\circ}$ La afinidad en segundo grado de línea colateral». (Canon 1042).

«En peligro de muerte, para atender a la conciencia, y si el caso lo pide a la legitimación de la prole, pueden los Ordinarios locales dispensar a sus súbditos, donde quiera que residan, y a todos los demás que se hallen dentro de su territorio,... de todos los impedimentos de derecho eclesiástico, tanto públicos como ocultos, y aun múltiples,... exceptuada la afinidad en línea recta con consumación del matrimonio, evitando el escándalo...». (Canon 1043).

«En las mismas circunstancias de las que se trata en el canon 1043, y solamente en aquellos casos en que ni aun se puede acudir al Ordinario del lugar, gozan de igual facul-

drid, 23. Castán Tobeñas, J. Ibídem, 123. Clemente de Diego, F. 1930. Instituciones de Derecho Civil Español. Madrid: Imprenta de Juan de Pueyo, 351-352.

${ }^{99}$ Para mayor información, ver: Corazón, R. 2009. «El impedimento matrimonial de Afinidad en el Derecho de la Iglesia Católica del siglo XX y principios del XXI». Colecçào Lusitania Canonica. Serie a Direito Canónico. Separata de: o Direito Canónico ao Serviço da Igreja: os 25 Anos do Código de Direito Canónico (1983-2008). Universidad Católica Portuguesa. Instituto Superior de Direito Canónico. Lisboa, 383-400. Ver: Corazón, R. 2010. «El impedimento matrimonial de Afinidad en el Derecho Canónico de la Iglesia Católica del siglo XX y principios del XXI». Ius divinum nella vita della Chiesa. Atti del XIII Congresso Internazionale di Diritto Canonico Venecia, 847-883. Istituto di Diritto Canonico San Pio X-Consociatio Internationalis Studio Iuris Canonico Promovendo. Studium Generale Marcianum. Venetiis: Marcianum Press.

${ }^{100}$ Código de Derecho Canónico de 1917 y legislación complementaria. MCMLXIX. Madrid: Biblioteca de Autores Cristianos. 
tad de dispensar tanto el párroco como el sacerdote que asiste al casamiento conforme al canon 1098, número $2^{\circ}$, como el confesor; pero éste solamente en el acto de la confesión sacramental y para el fuero interno». (Canon 1044).

«Los Ordinarios locales, sujetándose a las cláusulas contenidas al final del canon 1043, pueden conceder dispensa de todos los impedimentos de que se hace mención en el citado canon 1043, cuando el impedimento se descubre estando ya todo preparado para el casamiento y éste no puede diferirse sin peligro probable de un mal grave hasta que se obtenga de la Santa Sede la dispensa.

Esta facultad se extiende también a la revalidación del matrimonio ya celebrado si hay el mismo peligro en la demora y no hay tiempo de recurrir a la Santa Sede.

En las mismas circunstancias gozan de igual facultad aquellos de quienes se hace mención en el canon 1044, pero sólo en los casos ocultos en los que ni siquiera es posible recurrir al Ordinario local o no se puede hacer sin peligro de violación del secreto». (Canon 1045).

«La afinidad en línea recta dirime el matrimonio en cualquier grado; en línea colateral lo dirime hasta el segundo grado inclusive.

El impedimento de afinidad se multiplica:

$\left.1^{\circ}\right)$ Cuantas veces se multiplica el impedimento de consanguinidad del que procede;

$\left.2^{\circ}\right)$ Por la celebración sucesiva de matrimonios con los consanguíneos del cónyuge difunto». (Canon 1077).

"Cuando por un documento cierto y auténtico que no admite contradicción ni excepción de ninguna clase consta de la existencia del impedimento de ... afinidad... y cuando a la vez se sabe con igual certeza que no se ha concedido dispensa de este impedimento, puede en este caso el Ordinario, citadas las partes, declarar la nulidad del matrimonio sin sujetarse a las solemnidades hasta ahora mencionadas, pero interviniendo el defensor del vínculo». (Canon 1990).

El parentesco de afinidad despliega otros efectos jurídicos, que se hallan expuestos en los cánones $1520, \S 2,1540,1613,1755, \S 2,2^{\circ}, 1757, \S 2,3^{\circ}, 1974$, $2027, \S 1$ y $2293, \S 1$ y $\$ 4$.

\section{El Código de 1917 quedó derogado, al entrar en vigor el}

Corpus Iuris Canonici de $1983,{ }^{101}$ establece respecto a los efectos de la afinidad en el matrimonio:

«La afinidad surge del matrimonio valido incluso no consumado, y se da entre el varón y los consanguíneos de la mujer, e igualmente entre la mujer y los consanguíneos del varón.

Se cuenta de manera que los consanguíneos del varón son en la misma línea y grado afines de la mujer, y viceversa». (Canon 109).

«Los impedimentos se multiplican cuando provienen de diversas causas; pero no por repetición de una misma causa...». (Canon 1046).

«La afinidad en línea recta dirime el matrimonio en cualquier grado». (Canon 1092).

«Una vez recibida la petición hecha conforme al c. 1677, el Vicario judicial o el juez por éste designado puede declarar mediante sentencia la nulidad de un matrimonio,

\footnotetext{
${ }^{101}$ Código de Derecho Canónico de 1983. 1983. Pamplona: Ediciones Universidad de Navarra, S.A. Comentario exegético al Código de Derecho Canónico. 1996. Pamplona: Eunsa.
}

Hispania Sacra, LXIV

129, enero-junio 2012, 97-139, ISSN: 0018-215-X, doi: 10.3989/hs.2012.004 
omitiendo las solemnidades del proceso ordinario pero citando a las partes y con intervención del defensor del vínculo, si por un documento al que no pueda oponerse ninguna objeción ni excepción consta con certeza la existencia de un impedimento dirimente..., con tal de que conste con igual certeza que no se concedió dispensa...». (Canon 1686).

Otros efectos jurídicos del parentesco de afinidad quedan determinados en los cánones 492,\$3, 1078,§1 y §3,1079, 1080, 1298, 1448 y artículo 67 de la Instrucción Dignitas Connubii, ${ }^{102} 1449$ y artículo 68 de la Instrucción Dignitas Connubii y $1548, \S 2,2^{\circ}$ y artículo $194, \S 2,3^{\circ}$ de la Instrucción Dignitas Connubii.

Para la Iglesia Católica oriental rige el Código de Cánones de las Iglesias orientales de 1990.

Código de Cánones de las Iglesias Orientales de 1990, ${ }^{103}$ determina los efectos de la afinidad para el matrimonio del siguiente modo:

«La afinidad dirime el matrimonio en cualquier grado de la línea recta y en segundo grado de la línea colateral.

El impedimento de afinidad no se multiplica». (Canon 809).

"La afinidad surge del matrimonio válido, y se da entre un cónyuge y los consanguíneos del otro cónyuge.

En la línea y en el grado en que uno es consanguíneo de uno de los cónyuges, es afín del otro cónyuge». (Canon 919).

El parentesco de afinidad despliega otros efectos jurídicos, que se hallan recogidos en los cánones $122, \S 1,263, \S 3,1041$ y 1106 del C.C.E.O.

Actualmente y para la afinidad, la mayor diferencia entre la Iglesia Católica latina y la oriental es que para occidente solo hay impedimento matrimonial de afinidad en línea recta en todos sus grados (se necesita dispensa para contraer con suegra/o, hijastra/o), mientras que para oriente también existe impedimento de afinidad en segundo grado de la línea colateral, es decir, precisan dispensa para contraer con cuñada/o.

\section{CONCLUSIONES}

La investigación histórica, jurídica y religiosa llevada a cabo sobre la afinidad, permite contemplar a lo largo de estas páginas el progresivo desarrollo de la ley en la Iglesia y extraer, a modo de conclusión, los siguientes aspectos, nueve positivos y dos en los que es preciso mejorar:

\footnotetext{
${ }^{102}$ Instrucción Dignitas Connubii. 2005. Pontificio Consejo para los Textos Legislativos. En: www.vatican.va tianos.

${ }^{103}$ Código de Cánones de las Iglesias Orientales. MCMXCIV. Madrid: Biblioteca de Autores Cris-
} 
1.- La ley en la Iglesia ha ido perdiendo complicación, se ha simplificado, pasando del $7^{\circ}$ grado que, en la Edad Media, impedía el matrimonio entre parientes al primer grado y sólo en línea recta actual, desde 1983.

2.- En el cómputo del parentesco la Iglesia ha cambiado. Actualmente y desde 1983, tanto para la Iglesia como para la sociedad civil, el parentesco se computa de igual modo. Esto es bueno para cualquier católico, miembro de la sociedad civil y de la Iglesia.

3.- Hay mayor unión entre la Iglesia Católica latina y la oriental. Más trato y ayuda, respeto a las diferencias y al propio rito, y alabanzas recíprocas a santos y liturgia.

4.- Fuerte característica propia de la época actual es el ecumenismo, promoviendo y avanzando progresivamente en la unión de todos los cristianos.

5.- A lo largo de las páginas anteriores, se ha podido contemplar que la religión está inserta en la historia de la humanidad.

6.- También que, desde siempre, el matrimonio ha sido unión perdurable de hombre y mujer por la que constituyen su propia familia, institución que les sobrepasa a cada uno individualmente.

7.- El matrimonio es unión humana; pero, desde siempre y en todas las culturas, ha tenido también un sentido religioso.

8.- Que todo impedimento matrimonial obedece a una doble razón: ayudar a que los contrayentes se casen bien y proteger un bien superior.

9.- Con mayores atribuciones al ámbito particular, pues hasta el Código de 1983 la dispensa para poder contraer matrimonio por razón de impedimento de afinidad la concedía el Romano Pontífice, y, desde 1983, para el único caso en que se precisa dispensa, que es la afinidad en línea recta en todos sus grados, la otorga el Obispo, previa petición del interesado.

Pero también es dable apreciar un par de asuntos aun sin solventar que, dicho sea con todos los respetos debidos, urge mejorar, en bien de todos:

1.- En muchos casos, no se resuelven con la debida diligencia los asuntos, observando y cumpliendo los plazos establecidos.

Por ejemplo, para las Nulidades Matrimoniales, cumplir lo dispuesto en el canon $1453,{ }^{104}$ y en el artículo 72 de la Instrucción Dignitas Connubii, resolviendo en 1 año la Causa en primera Instancia y en otros 6 meses la segunda, en vez de que haya Causas, como sucede a veces, que se eternizan.

${ }^{104}$ Canon 1453 del C.I.C. de 1983: Los jueces y los tribunales han de cuidar de que, sin merma de la justicia, todas las causas se terminen cuanto antes, y de que en el tribunal de primera instancia no duren más de un año, ni más de seis meses en el de segunda instancia.

Hispania Sacra, LXIV

129, enero-junio 2012, 97-139, ISSN: 0018-215-X, doi: 10.3989/hs.2012.004 
Mi propuesta, para lograr la tan deseada y necesaria diligencia, es que el Tribunal, al finalizar el año, informe del número de Causas de Nulidad que le han entrado y del número que ha resuelto, como hace; pero, además, que también añada otra información: el número de Causas que siguen aún sin resolverse, a pesar de haber tenido su entrada hace 10, 9, 8, 7, 6, 5, 4, 3, 2 o 1 año, porque esto sí pone de manifiesto la verdadera realidad y servirá de alerta, tanto para el Tribunal que informa como para el que recibe esa información.

2.- Es aforismo que el río siempre vuelve a su cauce y, así, en los plazos procesales o ante registros hemos vuelto a las andadas, tal y como pasó en la Edad Media con el doble cómputo para el parentesco, hoy día felizmente superado.

Pues cabe preguntarse ¿cómo es posible que, en los plazos procesales civiles, se respete el domingo -el dies domine- y, sin embargo, no lo respete la Iglesia?, ¿qué sentido tiene?

En vía procesal o registral civil se denominan días hábiles ${ }^{105} \mathrm{y}$, lógicamente, de ellos se excluyen los domingos y las fiestas.

Sin embargo, la práctica eclesiástica incluye todos los días al llamado tiempo útil. Y con buena lógica, cabría oponer que días útiles, lo que se dicen útiles, lo serán para descansar, para meditar, pero no, desde luego, para realizar el acto judicial o administrativo de que se trate, pues el Tribunal o Registro está cerrado por vacaciones.

Pero además la ley no dice eso, pues, con buen sentido, el canon 201 del Código ${ }^{106}$ contrapone tiempo continuo a tiempo útil. Y hacer como se hace, que cuando el plazo acaba en fiesta se prorrogue hasta el primer día laborable, no transforma en útiles los días intermedios que no lo son.

Por tanto, por desgracia y para nuestro perjuicio, se constata que, en el cómputo de los días tratándose de días hábiles o útiles, en la práctica se ha vuelto a contemplar de dos modos diferentes una idéntica realidad: un modo para la práctica eclesiástica y otro, distinto, para la vida civil. Pues así se ha verificado

${ }^{105}$ Artículo 130 de la Ley de Enjuiciamiento Civil española. 1.- Las actuaciones judiciales habrán de practicarse en días y horas hábiles. 2.- Son días hábiles todos los del año, excepto los domingos, los días de fiesta nacional y los festivos a efectos laborales en la respectiva Comunidad Autónoma o localidad. También serán inhábiles los días del mes de agosto... Ley de Enjuiciamiento Civil. 2002. Madrid: Boletín Oficial del Estado.

Artículo 182,1. de la Ley Orgánica del Poder Judicial: Son inhábiles los domingos, los días de fiesta nacional y los festivos a efectos laborales en la respectiva Comunidad Autónoma o localidad. Artículo 183 de la Ley Orgánica del Poder Judicial: También serán inhábiles los días del mes de agosto para todas las actuaciones judiciales, excepto las que se declaren urgentes por las leyes procesales. Ley Orgánica del Poder Judicial. 1989. Madrid: Tecnos.

${ }^{106}$ Canon 201 del C.I.C. de 1983: \$1. Por tiempo continuo se entiende aquel que no admite ninguna interrupción. \$2. Por tiempo útil se entiende el que concierne a quien usa o reclama su derecho, de tal manera que no corre para quien ignora o no puede reclamar. 
que se interpreta en la Iglesia de España, Italia, Portugal, Chicago y en todos los países que en ellos se apoyan, es decir, en la generalidad.

En esta materia reina confusión, que podría dar lugar a abusos e incorrecciones. Mi propuesta es que, en bien de todos, bien merece un pronunciamiento del Pontificio Consejo para los Textos Legislativos, organismo eclesiástico competente.

\section{BiBLIOGRAFÍA}

Agustín, San. MCMLVIII. Contra Faustum manich., libri triginta tres. Del bien del matrimonio. De los enlaces adulterinos. Sobre el matrimonio y la concupiscencia. De civitate Dei. Qvaestionvm in Heptatevchvm, libri VII. Biblioteca de Autores Cristianos. Madrid.

Appendix Lex Romana Wisigothorum.

Alberigo, G. 1993. Historia de los Concilios Ecuménicos. Salamanca: Sígueme.

Aldwin, J. W. 1963 y 1965 «Critics of the Legal Profession Proceed» of the 2nd. Intern. Congress of Medieval Canon Law. Boston y Roma.

Aquino, Tomás de. Santo. 1852. Summa Theologica. Parmae: Typ. Petri Fiaccadori.

Arribas Garrido, F. 2002. Aurora de la Salvación. Segovia: Impresión: Taller Imagen (Segovia).

Bannon, C. J. 1997. The brothers of Romulus: fraternal Pietas in Roman law, literature, and society. Princeton, NJ: Princeton University Press.

Basilius, San. 1929. Tomus 29-32. Obras ascéticas de San Basilio. Lviv. 1964. Carta canónica de San Basilio a Amphilochio en Cartas elegidas de San Basilio el Grande, (traducción S. Fedyniak). New York.

Bergmann, E. 1953. Codex Hammurabi: textus primigenius. Roma: Editrice Pontificio Istituto Biblico.

Biblia. Antiguo Testamento. Nuevo Testamento.

Biondi, B. 1952-1954. Il Diritto Romano Cristiano. Milano.

Bonfante, P. 1925. Derecho de Familia. Roma: Atilio Sampaolessi Editore.

Bonfante, P. Resmancipi.

Bonfante, P. 1946. Istituzioni di Diritto Romano. Milano.

Bosch Gimpera, P. 1940. «España Romana (218 a.C a 414 d.C.)», en Menéndez Pidal, R. Historia de España. Madrid: Espasa Calpe.

Breves.

Brown, R. Fitzmyer y J. Murphy, R. 1972. «San Jerónimo», en Comentario Bíblico. Madrid: Ediciones Cristiandad.

Brugiere, M. B. 1979. Le mariage de Philippe Auguste et d'Isambour de Danemark. Toulouse: Mél Dauvillier.

Burchardo. Decreto. Patrología Latina. Database [Recurso electrónico]. Migne. París.

Canones et Decreta Concilii Tridentini ex Editione Romana a. MDCCCXXXIV. S. Congr. Card. Conc. Trid. Interpretum Declarationes ac Resolutiones ex ipso Resolutionum Thesauro Bullario Romano et Benedicti XIV s.p. operibus et Constitutiones 
Pontificiae Recentiores ad Ius Commune Spectantes e Bullario Romano Selectae. Lipsiae.

Capello, F. M. 1945. Summa Iuris Canonici: in usum scholarum: concinnata. Roma.

Casas, Bartolomé de las. 1869 y 1872. Summa conciliorum omnium ordinata. Pariis: editio recens opera ac studio M. L. Bail. Publicación: Fredericus Leonard y Summa conciliorum omnia tam generalium quam provincialium; collecta dum agere in Concilio Tridentino. Marietti.

Castán Tobeñas, J. 1976-87. Derecho Civil Español, Común y Foral. Madrid: Reus S.A.

Chantre, Pedro el. Verbum abbreviatum.

Chartres, Ivo de. Decretum, Panormia y Epístolas.

Clemente de Diego, F. 1930. Instituciones de Derecho Civil Español. Madrid: Imprenta de Juan de Pueyo.

Codex Gregorianus.

Codex Hermogenianus.

Codex Theodosianus.

Códice antiguo Vigilano, ms. D.I.2, de El Escorial, en letra visigótica.

Código Civil español. 2000. Madrid: Tecnos.

Código de Cánones de las Iglesias Orientales. MCMXCIV. Madrid: Biblioteca de Autores Cristianos.

Código de Derecho Canónico de 1917 y legislación complementaria. MCMLXIX. Madrid: Biblioteca de Autores Cristianos.

Código de Derecho Canónico de 1983. 1983. Pamplona: Ediciones Universidad de Navarra, S.A.

Código de Hammurabi.

Código Mesoasirio.

Collatio Mosaicarum.

Coll. 74T. 1973. Diuersorum patrum sententiae, siue Collectio in LXXI titulos digesta. Ciudad del Vaticano.

Comentario exegético al Código de Derecho Canónico. 1996. Pamplona: Eunsa.

Concilio de Trento. El Sacramento del matrimonio. Sesión XXIV. En: http://www.multimedios.org/docs/d000436/p000011.htm\#h1

Constantino. Constitución Ad Verinem Vicarium Africae.

Consultatio veteris.

Corazón, R. 2001 y 2003. Nulidades matrimoniales... que no lo separe el hombre. $3^{\circ}$ edición. Bilbao: Desclée de Brouwer y $4^{\mathrm{a}}$ edición en: www.autorescatolicos.org (Laicos. Rosa Corazón).

Corazón, R. 2003. Cásate y verás. Madrid: Marova. Corazón, R. 2007.

Corazón Corazón, María Rosa. 2007. La afinidad. ISBN: 978-84-669-3033-8. Depósito Legal: M-54932-2007. Tesis Doctorales. Facultad de Derecho. Ciencias Sociales. Servicio de Publicaciones. Universidad Complutense. Madrid. En:

http://www.ucm.es/BUCM/

http://www.ucm.es/BUCM/tesis/der/ucm-t30020.pdf

Corazón, R. 2009. «El impedimento matrimonial de Afinidad en el Derecho de la Iglesia Católica del siglo XX y principios del XXI». Colecçào Lusitania Canonica. Serie a Direito Canónico. Separata de: o Direito Canónico ao Serviço da Igreja: os 25 Anos 
do Código de Direito Canónico (1983-2008). Universidad Católica Portuguesa. Instituto Superior de Direito Canónico. Lisboa, 383-400.

Corazón, R. 2010. «El impedimento matrimonial de Afinidad en el Derecho Canónico de la Iglesia Católica del siglo XX y principios del XXI». Ius divinum nella vita della Chiesa. Atti del XIII Congresso Internazionale di Diritto Canonico Venecia, 847883. Istituto di Diritto Canonico San Pio X-Consociatio Internationalis Studio Iuris Canonico Promovendo. Studium Generale Marcianum. Venetiis: Marcianum Press.

Corpus Iuris Canonici. MDCCCLXXIX. Editio Lipsiensis Secunda post Aemilii Ludouici Richteri curas ad Librorum Manu Scriptorum et Editionis Romanae Fidem Recognouit et Adnotatione Critica instruxit Aemilius Friedbergs, pars prior Decretum Magistri Gratiani. Ex Officina Bernhardi Tauchnitz. Lipsiae.

Decretales pontificias. Colecciones de Decretales.

Deimel, A. 1930. Codex Hammurabi, textus primigenius. Romae: Sumptibus Pontificii Istituti Biblici.

Duby, G. 1977. Le mariage dans la société du haut Moyen Áge. «Il matrimonio nell'alto Medioevo». I. Settimane di Studio del Centro Italiano di Studi sull'Alto Medioevo. Spolète (Italy).

Edicto de Rothario.

Edicto de Teodorico.

El Sacrosanto y Ecuménico Concilio de Trento, traducido al idioma castellano por Don Ignacio López de Ayala. Agrégase el texto latino corregido según la edición auténtica de Roma, publicada en 1564. Quinta edición. Madrid.

Fedwick, P. J. 1979. Basil of Caesarea Christian, Humanist, Ascetic. Canadá: Pontifical Institute of Mediaeval Studies.

Fernández Espinar, R. 2003. Las prohibiciones de contraer matrimonio entre parientes en la época visigoda. Granada: Gráficas del Sur.

Fernández y Larrea, R. 1788 y 1827. Synodorum oecumenicarum summa, in qua praeter uniuscuiusque concilii historicam enarrationem, in médium etiam afferuntur canones universi, atque scholiis quibusdam elucidantur. Editio altera, novis curis elaborata, correctior \& adaucta ad usum verspertinae canonum cathedrae per... Raymundum Fernández \& Larrea. Vallisoleti. Apud viduam et filios. Santander y Typ. León Amarita. Matriti.

Ferrari, G. C. 1877. Summa Institutionum Canonicorum. Genuae: Typ. Archiepiscopali.

Filippi, M de. 1998. Fragmenta Vaticana: storia di un testo normativo. Bari: Cacucci, cop.

Finet, A. 1973. Le Code de Hammurabi. París: Éditions du Cerf.

Finkelstein, J. J. 1966. Sex Offenses in Sumerian Laws. Jaos.

Fragmenta Vaticana.

Freyer, H. y Hertz, F. 1945. El despertar de la Humanidad. Las culturas de los tiempos primitivos. Asia Oriental y Oriente mediterráneo. Madrid: Espasa Calpe.

Fuero Real. Leyes de Alfonso X. 2. Fuero Real. Edición y análisis crítico por Martínez Díez, G. con la colaboración de Ruiz Asencio, J. M. y Hernández Alonso, C. 1988. Ávila.

García-Villoslada, R. MCMLXXX. Historia de la Iglesia en España. Madrid.

García y García, A. 1981. Constitutiones Concilii quarti Lateranensis una cum commentariis glossatorum. Città del Vaticano. 
Gaudemet, J. 1993. El matrimonio en occidente. Madrid.

Gayo. Instituta. Comentario al Edicto provincial, libro VIII.

Ghirlanda, G. 1992. El derecho en la Iglesia misterio de comunión. Madrid: Ediciones Paulinas.

Godefroy, D. 1726. «Commentaire sur le Code Thèodosien» en Corpus Iuris Civilis Romani. Amberes. Gradenwitz. 1925.

Godefroy, J. 1665 y 1736-1745. Codex Theodosianus cum perpetuis commentariis J. Gothofredi... Pramittuntur chronologia accuratior, cum chronico historico, et prolegomena... opus posthumum... recognitum... opera et studio A. Marvillii. Lugduni. Other editions: Lipsiæ.

Gómez Morán, L. 1951. Teoría de los Impedimentos para el Matrimonio. Madrid.

González, F. A. Tejada y Ramiro, J. 1849-55. Colección de cánones y de todos los concilios de la Iglesia española. Madrid.

González Rivas, S. S. J. 1949. La penitencia en la primitiva Iglesia española. Salamanca.

Graciano. Decreto. Extraído de Monumenta Germaniae Historica. Edition Friedberg 1879.

Gradenwitz. 1925 y 1929. Heidelberger Index zum Theodosianus y Ergänzungsband zum Theodosianus. Berlín.

Gregor der Grosse. 1995. Von der Sehnsucht der Kirche. Freiburg.

Gregorio Magno, San. MCMLVIII. Regla pastoral. Obras. Biblioteca de Autores Cristianos. Madrid.

Hefele, K. J. von y Leclercq, H. 1907-1921. Histoire des Conciles d'après les documents originaux. París: Letouzey.

Henricus de Segusio. Summa Aurea o Summa Ostiense.

Hrozny, F. 1922. Code Hittite provenant de l'Asie Minuere. París. Neufeld, E. 1951. The Hittite Laws. London: Publication Name: Luzca \&Co.

Iglesias, J. 1965. Derecho Romano. Instituciones de Derecho Privado. Barcelona: Ediciones Ariel.

Instrucción Dignitas Connubii. 2005. Pontificio Consejo para los Textos Legislativos. En: www.vatican.va

Isidoro de Sevilla, San. MMIV. Orígenes o Las Etimologías. Biblioteca de Autores Cristianos. Madrid.

Ibán Iván, C. 2004. Manual de Derecho Eclesiástico. Madrid: Trotta.

Ivo, San. 1557. Pannormia seu Decretum D. Ivonis Carnothensis Episcopi restitutum. Lovanii, excudebat Stephanus Valerius, expensis Antonii Maria Bergaingne.

Jaffé, Ph. 882-1198. Regesta Pontificum Romanorum. Ed. S. Löwenfeld. Kaltenbrunner, F. (?-590) y Ewald, P. (590-882). 1885-1888. Leipzig Veit, reed. Graz. 1956. Verlagsanstalt: Akademische Druck-u.

Jedin, H. 1965. El Concilio de Trento en su última etapa. Crisis y conclusión. Barcelona: Editorial Herder y 1975. Historia del Concilio de Trento. Navarra: Eunsa.

Juan Pablo II. 2005. Memoria e identidad. Madrid: La esfera de los libros.

Justiniano. Codex. Institvtiones. Digestum o Pandectae: http://www.gmu.edu/departments/fld/CLASSICS/justinian.html

Klenze. 1828. Zeitschrift für geschichliche Rechtswissenchaft.

Kuttner, S. 1984. «Research on Gratian: Acta et Agenda». Proccedings of the Seventh International Congress of Medieval Canon Law. Cambridge. 
Lara Peinado, F. 1982. Código de Hammurabi. Madrid: Editorial Nacional.

Lex Alamannorum.

Lex Bajuvariorum.

Lex Pompeia de parricidis.

Lex Romana Burgundionum.

Lex Romana Wisigothorum.

Lex Salica a Carlo Magno emendata anno 768.

Lex Wisigothorum.

Ley de Enjuiciamiento Civil. 2002. Madrid: Boletín Oficial del Estado.

Ley Orgánica del Poder Judicial. 1989. Madrid: Tecnos.

Ley Papia.

Leyes de Luitprando.

Leyes Hititas.

Liber Iudiciorum.

Lindsay, W. M. 1911. Etymologiarum sive Originum libri, XX. Oxford.

Lombardo, Pedro. Sentencias.

Lozano Corbí, E. 1994. Sipnosis de Historia e Instituciones de Derecho Romano. Zaragoza: Mira.

Machuca, A. 1903. Los Sacrosantos Ecuménicos Concilios de Trento y Vaticano. Madrid: Librería católica de D. Gregorio Pérez del Amo.

Mansi, J. D. 1901-1927 y 1960. Sacrorum Conciliorum Nova et Amplissima Collectio. Parisiis: Akademische Druck-U y Graz-Austria: Verlagsanstalt.

Martínez Díez, G. 1984 y 1992. La colección canónica hispana. Concilios hispanos. Concilios galos. Madrid.

Meyer, P. M. 1905. Theodosiani, libri XVI cum Constitutionibus Sirmondianis et Leges Novellae ad Theodosianum pertinentes. Berolini: Ed. Th.

Migne, J. P. 1857-1866. Patrologiae cursus completus. Series graeca. PG. París.

Miscelánea conmemorativa del Concilio de Trento (1563-1963). 1965. Estudios y documentos. Consejo Superior de Investigaciones Científicas. Instituto Enrique Flórez. Madrid-Barcelona.

Molina, M. 2000. La ley más antigua. Textos legales sumerios. Barcelona: Trotta edicions de la Universitat de Barcelona. Pliegos de Oriente.

Mommsen, T. 1905. Theodosianus Codex et Novellae. Berolini: Ed. Th. Mommsen et P. Meyer. Meyer, P. M. 1905.

Mommsen, T. 1999. Derecho Penal Romano. Pamplona: Analecta Editorial.

Montemayor Aceves, M. E. 1994. Comparación de leyes mosaicas y romanas. México.

Monumenta Germaniae Historica. MGH. 1828, 1879 y 1916. Hahn, varias impresiones, Hannover: Edition Friedbergs y Berlin: Editada por Deutschen Akademie der Wissenschaften.

Monumenta Iuris Canonici. 1965. Ciudad del Vaticano: Biblioteca Apostólica Vaticana, [varias impresiones].

Novísima Recopilación.

Ortolán, M. 1873. Explicación histórica de las Instituciones del Emperador Justiniano precedida de la Historia de la Legislación Romana. Madrid: Librería de D. Leocadio lópez, editor.

Papinianus. Responsa. Sententias.

Hispania Sacra, LXIV

129, enero-junio 2012, 97-139, ISSN: 0018-215-X, doi: 10.3989/hs.2012.004 
Partidas. Las siete Partidas del sabio Rey don Alonso el nono, nueuamente glosadas por el licenciado Gregorio López... 1555. Salamanca.

Paulus. Sententiae. Collatio. Liber singulari ad Senatusconsultum Turpillianum. Liber sing. de gradibus et adfinibus et nominibus eorum.

Pavia, Bernardo de. Summa Decretalium.

Peñafort, Raimundo de, San. Summa de Matrimonio.

Perozzi, S. 1906. Istituzioni di diritto romano. Firenze: Barbera.

Pitra. 1864-1868. Iuris Ecclesiastici Graecorum historia et monumenta. Romae.

Pomponius. Liber IV ex Plautio.

Pontificia Comisión Bíblica. 1993. La interpretación de la Biblia en la Iglesia. Città del Vaticano: Librería Editrice Vaticana.

Pritchard, J. B. 1966. La sabiduría del Antiguo Oriente. Barcelona: Garriga.

Quasten, J. 1977. Patrología 2. Madrid.

Real Cédula dada por Felipe II en Madrid a 12 de julio de 1564.

Ritzer, K. 1970. Le mariage dans les Églises chrétiennes du Ier au XI siècle. París: Cerf.

Rosset, M. 1895-1896. De sacramento matrimonii. Tractatus dogmaticus, moralis, liturgicus et iudiciarius. S. Joannis Maurianae, apud acturorem.

San Victor, Hugo de. 1485. De sacramentis christianae fidei. PL, T. 176, y Typ. Jordani: «Sermones» (H.9438), Strasbourg.

Sanmartín, J. 1999. Códigos legales de tradición babilónica. Barcelona: Editorial Trotta.

Spadafora, F. 1963. Dizionario Bíblico. Roma.

Spartien. Vie d'Antonin Caracalla.

Suberbiola Martínez, J. 1987. Nuevos concilios hispano romanos de los siglos III y IV. La colección de Elvira. Málaga.

Summa.

Theodosiani, libri XVI cum Constitutionibus Sirmondianis et Leges Novellae ad Theodosianum pertinentes. Berolini: Ed. Th. Mommsen et P. Meyer.

Tillemont, L. de. 1720. Histoire des empereurs et des autres princes qui ont regné durant les six premiers siecles de l'Eglise. París: Chez Charles Robustel.

Troplong, M. 1843. De l'influençe du christianisme sur le droit civil des Romains. París. Ulpiano. Liber regularum singulari. Liber XXVI ad Sabinum.

Vega Gutiérrez, A. M. 1997. La unidad del matrimonio y su tutela penal: precedentes romanos y canónicos del delito de bigamia. Granada: Comares.

Vives, J. MCMLXIII. Concilios visigóticos e hispano-romanos. Barcelona-Madrid.

Vives, J. Marín, T. y Martínez, G. 1963. Concilios visigóticos e hispanoamericanos. Barcelona-Madrid.

Voigt. Ius naturale.

Wieacker. 1960. Textstufen klassischer Juristen. Gotinga.

Winroth, A. 2000. The making of Gratian's Decretum. Cambridge, monografía cuyo núcleo central fue su tesis doctoral en la Universidad de Columbia: The Making of Gratian's Decretum. (Columbia University 1996. University Microfilms Inc. [UMI], Ann Arbor-Michigan, 9706925) y «The two recensions of Gratian's Decretum». Xth International Congress of Medieval Canon Law de 1996 en Syracuse (New York), Ius Ecclesiae 9 (1997): 221-264.

Zacarías, San. Papa. Carta Gaudio Magno. 